\title{
Inflation and real activity with firm-level productivity shocks*
}

\author{
Michael Dotsey, Robert G. King and Alexander L. Wolman ${ }^{\dagger}$ \\ February 1, 2009 \\ Preliminary and Incomplete
}

\begin{abstract}
Recent measurements of the extent of price stickiness indicate that prices remain fixed for a significant period of time, but that there is also a substantial amount of relative price variability. Extending our prior state-dependent pricing model to a setting in which there are discrete "micro states" interpreted as stochastic productivity variations at the firm level, we study the model's ability to match the micro evidence on price setting as well as its ability to generate persistent real responses to a money supply shock. We find that the model is rich enough so that its steady state can be calibrated to match the distribution of price changes reported in Klenow and Kryvtsov (2008). Given this calibration, the model is also capable of producing substantial persistence of output and inflation in response to shocks to money growth.

The model's flexibility also allows us to parameterize it in ways that generate behavior consistent with some recent studies in the literature, namely Midrigan (2006) and Golosov and Lucas (2008). We can also use simple versions of the model to understand the relationships between price adjustment at the micro level and aggregated statistics such as the hazard rate. In particular, we find that the model is capable of producing flat hazards at the macro level, even though any firm who has just changed its price faces the upward sloping hazard common in state dependent models.
\end{abstract}

\footnotetext{
${ }^{*}$ Andrew Foerster and Michael Johnston provided outstanding research assistance. This paper does not represent the views of the Federal Reserve System or the Federal Reserve Banks of Philadelphia or Richmond.

${ }^{\dagger}$ Federal Reserve Bank of Philadelphia; Boston University, Federal Reserve Bank of Richmond and NBER; Federal Reserve Bank of Richmond.
} 


\section{Introduction}

The search for a satisfactory macroeconomic model that embeds price stickiness using well articulated microeconomic foundations is an ongoing process. The myriad of papers that continue to employ time-dependent pricing mechanisms indicates the difficulties in meeting this challenge. It also makes many of the conclusions drawn from these papers suspect. The challenge has become especially glaring given the explosion of studies that describe the behavior of prices at the micro level. That data indicates a number of important features in price setting that are common across many countries. Namely, prices are set infrequently with the median length of time between price changes around eight months, and price changes are frequently small, but also frequently very large. Further, aggregate hazard rates are at

first downward sloping and then flat. As Alvarez (2007) points out, these features of the data are not well captured in the vast majority of frequently used New Keynesian models.

This paper develops a model that is both consistent with the distribution of price changes documented by Klenow and Kryvtsov (2007) in U.S data and that implies significant stickiness at the macro level. The model falls within the class of state dependent pricing models driven by fixed costs of price adjustment. As Golosov and Lucas (2007) observe, "The fact that many individual goods prices remain fixed for weeks or months in the face of continuously changing demand and supply conditions testifies conclusively to the existence of a fixed cost of repricing." That firms would take into account the current state of the economy when making those decisions seems equally compelling.

In choosing this model setting, we do not wish to imply that the model captures all aspects of price setting behavior. We fully recognize that pricing decisions are more complex and varied than the stark representation that characterizes our model. However, we believe that models in the class we are considering represent a better characterization of price setting than existing time-dependent models, and that in this class of models ours most fully replicates the features of the micro-data. Further, the modeling structure is sufficiently general that we can nest much of the recent work on state-dependent pricing with heterogenous firms.

The flexibility and richness of the model also allows us to explore the features of the model environment that are most important for replicating the various statistics that describe the micro-data, in particular the distribution of price changes. We can also explore the dynamic consequences of the model when only certain moments of the micro data are replicated, and thus indicate why existing models in this class achieve the results that they do.

We are able to match the micro evidence on price setting by taking seriously both the considerable differences in productivity across producers at a given time as well as the considerable uncertainties about a given producer's productivity over time. Thus, our paper 
falls within the class of current research on state-dependent pricing of Golosov and Lucas (2007), Midrigan (2006), Burstein and Hellwig (2007), Gertler and Leahy (2008), and Nakamura and Steinson (2008). As in these papers, our framework allows us to analyze the stochastic heterogeneity in prices and productivity at the microeconomic level with the goal of studying the following five topics that we consider to be critical for the ongoing analysis of state-dependent pricing.

1. the relationship of price-adjustment hazards at the level of individual firms and the extent of micro-level productivity fluctuations;

2. the implications of micro productivity fluctuations for the cross-sectional distribution of relative prices and the distribution of nominal price changes;

3. the consequences of adding microeconomic productivity uncertainty to the dynamic interaction of inflation and output;

4. the evaluation of the strength of general equilibrium effects on firm and aggregate patterns of price adjustment;

5. the consequences of alternative monetary policy rules for the dynamics of inflation and output.

The current "microstate" framework extends our prior state-dependent pricing model Dotsey, King and Wolman [1999] - to incorporate fluctuating microeconomic productivity with an eye to studying issues raised by two sets of recent research. As mentioned, recent empirical studies of microeconomic price dynamics by Bils and Klenow [2004], Klenow and Kryvtsov [2007], Midrigan [2006], and Nakamura and Steinson [2007] for the U.S, and the various papers in the Eurosystem Inflation Persistence Network on price setting in Europe. suggest that there is a great deal of relative price volatility and price flexibility, as measured by the average magnitude of price changes and by the frequency of price changes.

Second, recent theoretical studies by Klenow and Kryvtsov [2007], Golosov and Lucas [2007] and Midrigan [2006] are skeptical about aspects of previous SDP models. Notably, Golosov and Lucas [2007] argue that (i) idiosyncratic cost-type shocks are necessary for matching the micro data on price adjustment, and (ii) when such shocks are incorporated in a state-dependent pricing model, there is very little nonneutrality. In essence, Golosov and Lucas argue that the exact neutrality result of Caplin and Spulber [1987] is a reasonable guide to the aggregate implications of state-dependent pricing. On the other hand, Klenow 
and Kryvtsov [2007] study the consistency between the DKW model - in which there are no idiosyncratic productivity shocks - and data on the frequency of price adjustment. They argue that a realistic calibration requires that there be such strong assumptions on adjustment costs that the DKW model delivers essentially the same macro implications as a time dependent pricing (TDP) model built along Calvo [1983] lines. Finally, like Golosov and Lucas, Midrigan [2006] constructs a state-dependent pricing model with idiosyncratic shocks, but Midrigan argues that the model is consistent with significant non-neutralities, in contrast to Golosov and Lucas. Key to his result are the assumptions that there are a greater number of small idiosyncratic shocks which arise from the feature that multi-product firms face economies of scale in price adjustment.

Our prior research suggests the existence of an important middle ground in which there are both substantial non-neutralities and in which SDP models have very different implications from TDP models. On one level, the original DKW model was constructed precisely to allow for analysis of state-dependent pricing in environments that were richer and more realistic than those of the early works of Caplin and Spulber [1987] and Caplin and Leahy [1991], where monetary shocks were neutral either toward output or the price level. Working in a quantitative general equilibrium model, we showed that incorporating SDP into a standard modern model led to transitory dynamics in both the price level and output in response to a monetary shock. We argued that the details of these responses would depend in important ways on the structure of the model: on the average rate of inflation, on the monetary policy rule, on the behavior of marginal cost, on the elasticity of demand and so on. In the richer pricing setting analyzed in this paper, we wish to revisit a number of these points.

To that end, we begin in section 2 with a description of the model paying particular close attention to the details of individual firm pricing decisions. Then, in section 3 we consider the steady-state of our model framework, displaying how it can be used to make predictions about the panel data like that studied by Klenow and Kryvtsov (2007) or the member teams from the Inflation Persistence project. In section 4, we turn to macroeconomic dynamics. We find that there are indeed important implications of adding microstates. In particular, we find that adding microstates has major effects on impulse responses to monetary disturbances and that the responses in the micro state model are ones that would appear more realistic to a typical macroeconomist. In section 5 we investigate the role that monetary policy plays on the behavior of our model economy. Section 6 concludes. 


\section{The Model}

The basic elements of the model are similar to those described in Dotsey, King and Wolman [1999]. However, we now include heterogeneity across firms. Here we concentrate on firm level differences in productivity, but the framework can easily incorporate firm specific demand disturbances. After analyzing the stochastic adjustment framework, we describe the fairly standard features of the rest of the model.

\section{A stochastic adjustment framework}

To study the effect of serially correlated firm-level shocks, which we call microstates, we extend the framework of DKW [1999] with an eye to retaining the tractable general equilibrium analysis that can be conducted in that setting.

\subsection{Discrete microstates governed by a Markov chain}

The microstate of a firm is given by its productivity level, which we call $e_{t}$. We assume that there are $K$ different levels of microproductivity that may occur, $\underline{e}_{k}, k=1,2, \ldots K$, so that a firm of type $k$ at date t has total factor productivity

$$
a_{k t}=a_{t} \underline{e}_{k}
$$

where $a_{t}$ a common productivity shock work. We assume that the micro productivity levels are ordered so that $\underline{e}_{1}<\underline{e}_{2}<\ldots \underline{e}_{K}$.

Transitions between microstates are governed by a state transition matrix, $\mathrm{Q}$, where

$$
q_{k f}=\operatorname{prob}\left(e_{t+1}=\underline{e}_{f} \mid e_{t}=\underline{e}_{k}\right)
$$

For ease, we also use the notation $q\left(e^{\prime} \mid e\right)$ to denote the conditional probability of state $e^{\prime}$ occurring next period if the current state is $e$.

We assume that these transitions are independent across firms and that there is a continuum of firms, so that the law of large numbers applies. The stationary distribution of firms across microstates is then given by a vector $\Phi$ such that

$$
\Phi=Q^{T} * \Phi
$$

That is, the $k^{\text {th }}$ element of $\Phi$ (denoted $\phi_{k}$ ) gives the fraction of firms in the $k^{\text {th }}$ micropro- 
ductivity state (these firms have productivity level $\left.\underline{e}_{k}\right){ }^{1}$

\subsection{Optimal pricing and adjustment}

Consider a firm which faces a demand $d(p, s) y(s)$ for its output if it is charging a relative price $p$ in aggregate state $s$. Following DKW, we assume that this firm faces a fixed labor cost of adjustment $\xi$, which is drawn from a continuous distribution with support $[0, \mathcal{B}]$.

We find it convenient to describe the optimal adjustment of this firm as involving three value functions:

- its value if it does not adjust, which we call $\underline{v}$;

- its value if it has a current adjustment cost realization of 0 , which we call $v^{o}$.

- its maximized value given its actual adjustment cost $\xi$, which we call $v$.

That is, the market value of a firm is governed by

$$
v(p, e, s, \xi)=\max \left\{\underline{v}(p, e, s, \xi),\left[v^{o}(e, s)-\lambda(s) w(s) \xi\right]\right\}
$$

if it has relative price $p$; microstate $e$; macrostate $s$; and a stochastic adjustment cost draw of $\xi ; \lambda(s)$ is the marginal value of state contingent cash flows and $w(s)$ is the real wage. This market value is the maximum of two components, which are its value conditional on adjustment $\left(\left[v^{o}(e, s)-\lambda(s) w(s) \xi\right]\right)$ or nonadjustment $(\underline{v}(p, e, s, \xi))$.

The nonadjustment value $\underline{v}$ obeys the Bellman equation,

$$
\underline{v}(p, e, s)=\left[\lambda(s) z(p, e, s)+\beta E v\left(p^{\prime}, e^{\prime}, s^{\prime}, \xi^{\prime}\right) \mid(p, s)\right]
$$

with $p^{\prime}=p / \pi\left(s^{\prime}\right)$. That is, the value $\underline{v}$ is based on continuing with the current relative price $p$ for at least one additional period: it is based on $\lambda(s)$; the flow of real profits $z(p, e, s)$; and the discounted expected future value $\beta E v\left(p^{\prime}, e^{\prime}, s^{\prime}, \xi^{\prime}\right)$, given that $p^{\prime}=p / \pi\left(s^{\prime}\right)$.

The "costly adjustment value" is given by the value of the firm if it is free to adjust, $v^{o}(e, s)$, less the cost of adjustment, which depends on the macro state through $\lambda(s) w(s)$ and also on realization of the random adjustment cost $\xi$. In turn, the "free adjustment value" $v^{o}$ obeys

$$
v^{o}(e, s)=\max _{p^{*}}\left\{\lambda(s) z\left(p^{*}, e, s\right)+\beta E v\left(p^{\prime}, e^{\prime}, s^{\prime}, \xi^{\prime}\right)\right\}
$$

\footnotetext{
${ }^{1}$ The stationary probability vector can be calculated as the eigenvector associated with the unit eigenvector of the transpose of $Q$. See, for example, Kemeny and Snell (1976).
} 
with $p^{\prime}=p^{*} / \pi\left(s^{\prime}\right)$.

Notice that there are asymmetries in the determinants of these values. The nonadjustment value $\underline{v}(p, e, s)$ depends on the relative price, the microstate and the macro-state but not on the adjustment cost $\xi$ because this is not paid if adjustment does not take place. The free adjustment value $v^{o}(e, s)$ does not depend on the relative price (since the firm is free to choose a new price) or the adjustment cost $\xi$ (since the adjustment decision involves a fixed cost).

\subsection{Optimal adjustment}

As in other generalized partial adjustment models, such as the prior DKW analysis of price adjustment, the firm adjusts if

$$
\left[v^{o}(e, s)-\lambda(s) w(s) \xi\right]>\underline{v}(p, e, s) .
$$

Accordingly, there is a threshold value of the adjustment cost, such that

$$
\underline{\xi}(p, e, s)=\frac{v^{o}(e, s)-\underline{v}(p, e, s)}{\lambda(s) w(s)}
$$

Firms facing a lower cost of adjusting adjust and those with a higher cost charge the same nominal price as they did last period implying that their relative price falls.

The fraction of firms that adjust, then, is

$$
\alpha(p, e, s)=G(\underline{\xi}(p, e, s))
$$

where $G$ is the cumulative distribution of adjustment costs. The adjustment decision depends on the state of the economy, but it also depends on the distribution of adjustment costs, both directly and through the incentives that firms have to wait for a low adjustment cost realization. Importantly, because the costs of adjusting are bounded above and inflation continually erodes a firms relative price if it does not adjust, there will exist a maximum number of periods over which a firm may choose not to adjust its price. Because historical prices depend on the state, $h$, that a firm was in when it last adjusted as well as the state, $k$, that it is currently in, this maximal number, $J_{h k}$, will depend on both these states. Thus, in what follows the distribution that describes our economy takes on a finite but potentially large number of elements.

Further, the distribution of costs facing a firm is designed to be rather general. As in DKW, we employ a distribution based on the arctan function, but a beta distribution 


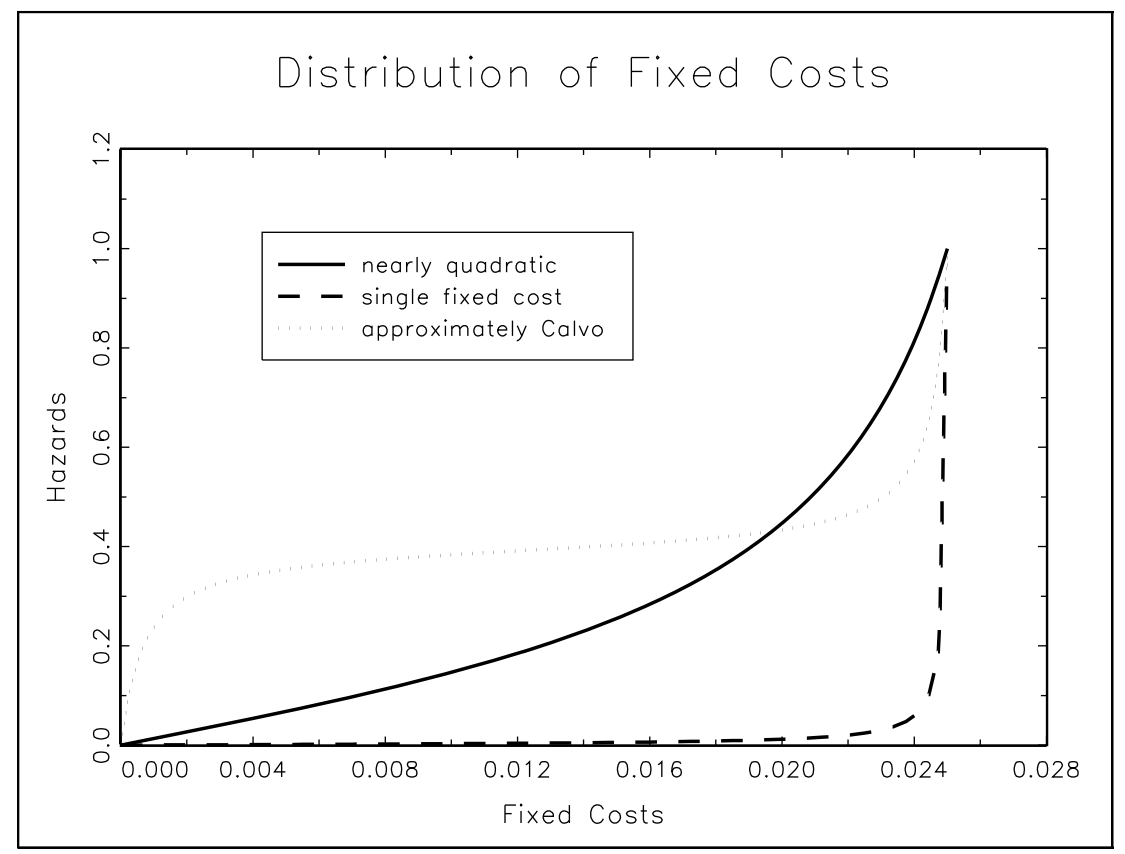

Figure 1:

would work equally well. This distribution allows us to approximate a single fixed cost of adjustment, costs of adjustment that would yield Calvo style hazards, or those that yield the nearly quadratic hazards used in Cabellero and Engle. Figure (1) gives examples of parameterizations of the cost function that would yield these cases.

\subsection{Dynamics and accounting}

A key feature of our framework is that we will track a distribution of firms that depends on previously set prices and on evolving levels of micro productivity, since we want to study the effects of this joint distribution on macroeconomic activity. Although the decision problem of firms was formulated above without reference to the sort of vintage structure employed in $\mathrm{DKW}$, it is useful to develop this structure for the purpose of tracking the distribution of relative prices, both for conceptual and computational reasons. In this context, we also introduce explicit dates.

The core mechanics are as follows. We start with a joint distribution of relative prices and productivity which prevailed last period. This distribution is then influenced by the effects of microproductivity transitions $(Q)$, the adjustment decisions of firms $(\alpha(p, e, s))$; and the effects of inflation on relative prices. The net effect is to produce a new distribution 
of relative prices prevailing in the economy. Table 1 summarizes some of the key notation and equations.

Table 1: Conceptual and accounting elements in microstate model

\begin{tabular}{|l|l|l|}
\hline \hline Concept & Symbol & Comment \\
\hline past relative price & $p_{j-1, h, t-1}$ & $h=$ historical state when price set $($ at $t-j)$ \\
\hline past fraction & $\omega_{j-1, h, l, t-1}$ & $l=$ microstate at t- 1 \\
\hline current fraction & $\theta_{j, h, k, t}$ & $\theta_{j, h, k, t}=\sum_{l} q_{l k} \omega_{j-1, h, l, t-1}$ \\
\hline adjustment rate & $\alpha_{j, h, k, t}$ & depends on $e, p, s$ \\
\hline current relative price & $p_{j, h, t}$ & $p_{j h t}=p_{j-1, t, t-1} / \pi_{t}$ \\
\hline current fraction & $\omega_{j, h, k, t}$ & $\omega_{j h k t}=\left(1-\alpha_{j k h t}\right) \theta_{j k h t}$ \\
\hline
\end{tabular}

Initial conditions and sticky prices. Let $p_{j-1, h, t-1}$ be the last period's relative price of a firm which last changed its price at date $t-1-(j-1)=t-j$ when it was in microstate $h$. Let $\omega_{j-1, h, l, t-1}$ be the fraction of firms in this situation, which charged this price and also had productivity level $l$. This information gives the joint distribution of productivity and prices at date t-1.

If such a firm chooses not to adjust, its relative price evolves according to

$$
p_{j h t}=p_{j-1, h, t-1} / \pi_{t}
$$

where $\pi$ is the current inflation rate $\left(\pi_{t}\right.$ is short-hand for $\pi\left(s_{t}\right)$ from above). That is, one effect on the date $t$ distribution of relative prices will be the effects of inflation.

Endogenous fractions: There are two micro shocks which hit a firm in our model, so that its ultimate decisions are conditioned on its productivity $(e)$ and its adjustment cost $(\xi)$. For the purpose of accounting in our model, we find it convenient to specify that the productivity shock occurs first and then the adjustment cost shock.

As above, let $\omega_{j-1, h, l, t-1}$ be the fraction of firms which charged the price $p_{j-1, h, t-1}$ when they were in microstate $l$ last period. As a result of stochastic productivity transitions, 
then, there will be a fraction

$$
\theta_{j, h, k, t}=\sum_{l} q_{l k} \omega_{j-1, h, l, t-1}
$$

of firms that start period t with a $j$ period old nominal price set in micro state $h$ and have a microstate $k$ in the current period.

However, not all of these firms will continue to charge the nominal price which they set in the past. To be concrete, consider firms with a $j$ period old price which they set in microstate $h$ and are now in $k$. Of these firms, let the adjustment rate be

$$
\alpha_{j h k t}
$$

Then, the fraction of firms choosing to continue charging the nominal price set $\mathrm{j}$ periods ago will be

$$
\omega_{j h k t}=\left(1-\alpha_{j h k t}\right) \theta_{j h k t}
$$

Taking all of these features into account, we can see that transitions are governed by two mechanisms: the exogenous stochastic transitions of the microstates $\left(q_{l k}\right)$ and the endogenous adjustment decisions of firms $\left(\alpha_{j h k t}\right)$. As discussed in prior sections, the adjustment decision depends on the firm's relative price, its microstate and the macroeconomic states in ways that introduce separate effects of $j, k, h$.

Given that firms currently in microstate $k$ adjust from a variety of historical states, it follows that the fraction of adjusting firms is given by

$$
\omega_{0 k k t}=\sum_{j} \sum_{h} \alpha_{j h k t} \theta_{j h k t}
$$

We use the redundant notation $\omega_{0 k k t}$ to denote the fraction of adjusting firms in microstate $k$ so that this is compatible with (9).

Since the distribution of microstates is assumed to be stationary, there is a constraint on the fractions,

$$
\phi_{k}=\omega_{0 k k t}+\sum_{h} \sum_{j} \omega_{j h k t}
$$

which is another way of describing the fraction of firms that are setting price and are in current microstate $k\left(\omega_{0 k k t}\right)$. 


\subsection{State variables suggested by the accounting}

There are two groups of natural endogenous state variables of the model suggested by the discussion above. One is the vector of past relative prices $p_{j-1, h, t-1}$ for $h=1,2, \ldots K$ and for $j=1,2, \ldots J_{h}$. The other is the fraction of firms that enter the period with a particular past microstate $(l)$ and a relative price that was set $j$ periods ago in microstate $h$.

$$
\omega_{j-1, h, l, t-1}
$$

Thus, the addition of microstates raises the dimension of the minimum state space elements introduced by the stochastic adjustment model structure from roughly $2 * J$ to roughly $J * K+$ $J * K^{2}$, where $J$ is the maximum number of periods of nonadjustment and $K$ is the number of microstates. However, this is only an approximation because the maximum number of periods can differ across microstates: $J_{k h}$ is the endpoint suitable for firms currently in microstate $k$ which last adjusted in historical microstate $h$.

\subsection{The adjustment process}

The dynamics of adjustment are highlighted by two figures.

Figure (2) shows the dynamics of adjustment with microstates. For each price lag (j-1), microstate last period (l) and historical state (h), a fraction $\omega_{j-1, h, l, t-1}$ enters the period. Call the matrix of these initial conditions $\omega_{j-1, t-1}$. Then, the microstate transition process

leads to a fraction of firms $\theta_{j h k t}=\sum_{l} q_{l k} \omega_{j-1, h, l, t-1}$ having a price lag $j$, a current microstate $k$; and a historical state $(h)$. Of these, a fraction $\alpha_{j h k t}$ of these firms chooses to adjust while a fraction $\eta_{j h k t}=1-\alpha_{j h k t}$ chooses not to adjust, leaving $\omega_{j h k t}=\eta_{j h k t} \theta_{j h k t}$ charging relative price $p_{j h t}$ and experiencing microstate $k$.

One thing which is important to stress, at this stage, is that we allow for zero adjustment or for complete adjustment in various situations (particular $\mathrm{j}, \mathrm{k}, \mathrm{h}$ entries)Figure 3 shows the determination of the adjustment fraction, which depends on the gain from adjusting relative to the cost from adjusting. In this figure, there is a generic adjustment cost function (the solid line) and the benchmark adjustment hazards from the model with Dixit-Stiglitz demand studied in Dotsey and King [2005]. 
Microstate Model

Evolution of fractions of price-setters:

Exogenous transitions ( $Q$ ) and endogenous hazards (a)

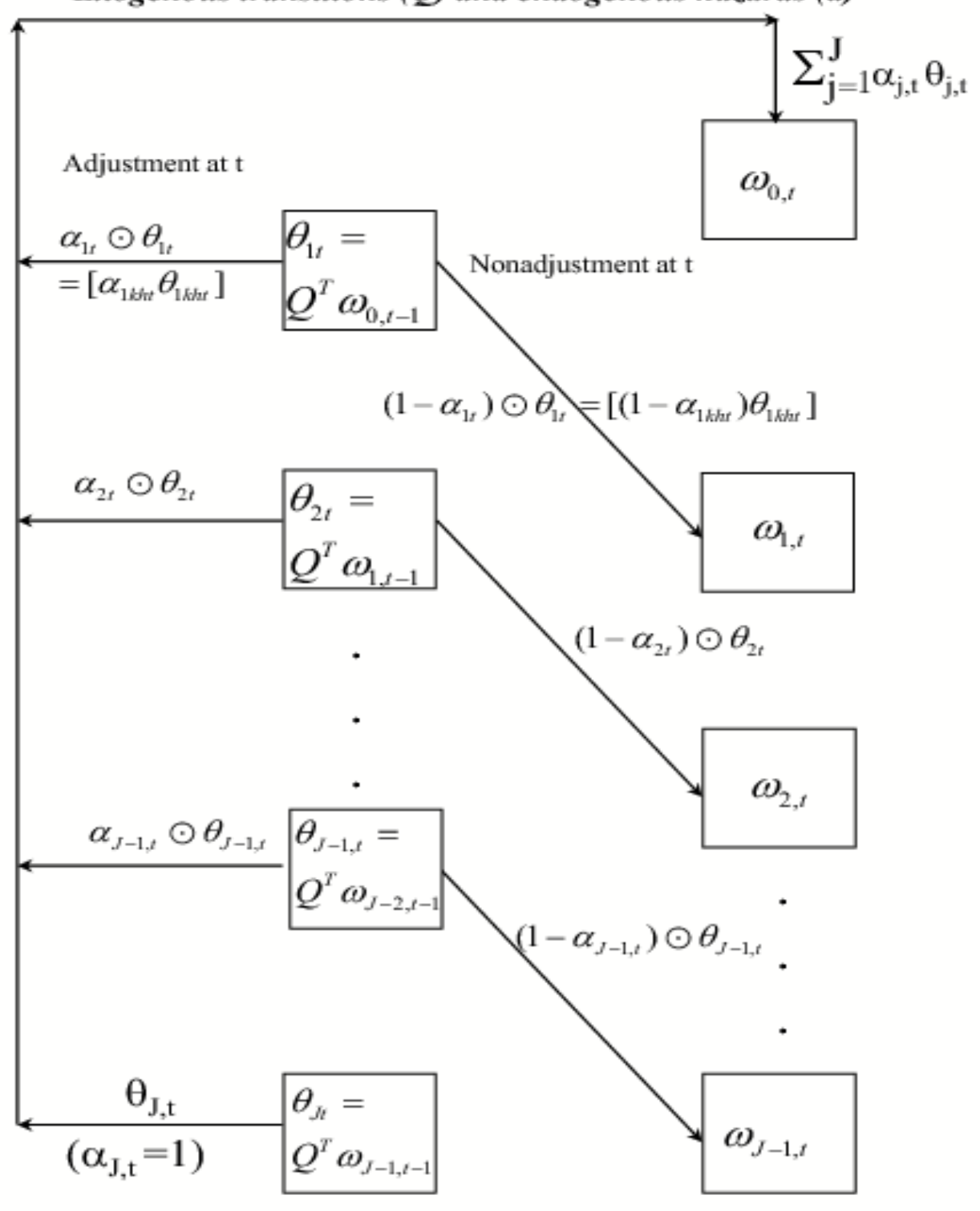

Date t: micro shocks

Date $\mathrm{t}+1$ and initial conditions initial conditions

Figure 2: 
Costs and benefits determine the stochastic adjustment rate

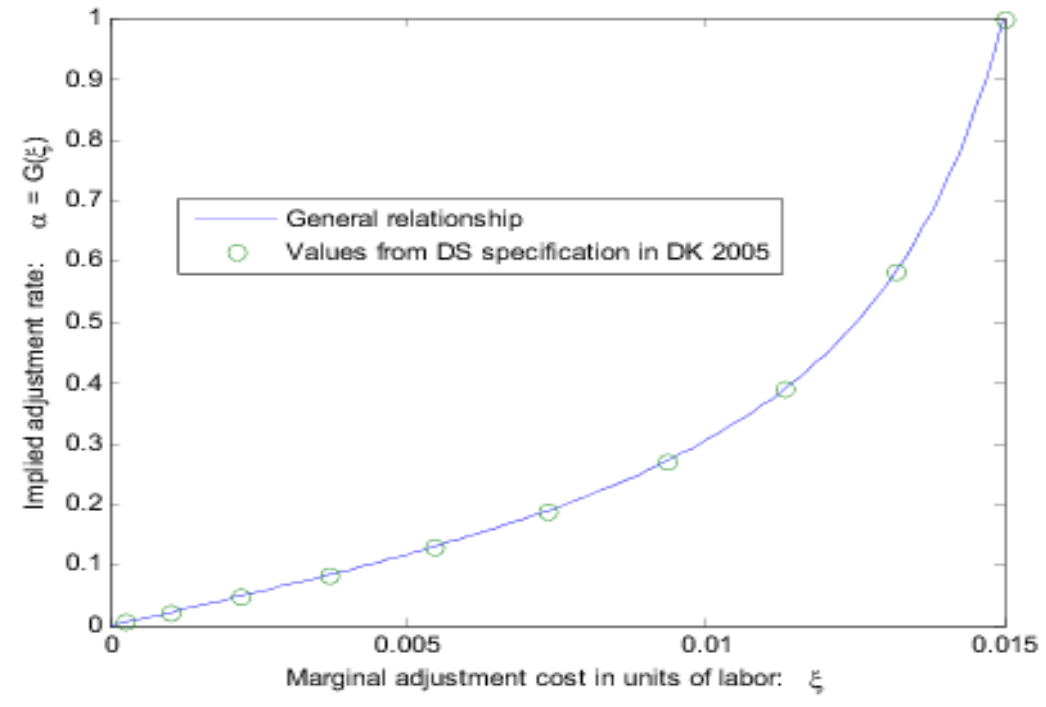

Figure 3: 


\section{A particular DSGE model}

We now imbed this generalized partial adjustment apparatus into a particular DSGE model, which is designed to be simple on all dimensions other than pricing so as to make clear the consequences of that mechanism. The starting point for our analysis is the analysis of Dotsey and King [2005], which shows that state-dependent pricing can be important for the dynamics of inflation and output. Throughout, we focus on a setting in which there is an economy-wide factor market for the sole input, labor.

\subsection{The Household}

As is conventional, there are two parts of the specification of household behavior, aggregates and individual goods.

\subsubsection{Aggregates}

We assume that there are many identical households that maximize

$$
\begin{gathered}
\max _{c_{t}, n_{t}} E_{0}\left\{\sum_{t} \beta^{t}\left[\frac{1}{1-\sigma} c_{t}^{1-\sigma}-\frac{\chi}{1+\gamma} n_{t}^{1+\gamma}\right]\right\} \\
\text { subject to: } c_{t} \leq w_{t} n_{t}+\sum_{j} \sum_{k} \sum_{k} \omega_{j h k t} z_{j h k t}
\end{gathered}
$$

where $c_{t}$ and $n_{t}$ are consumption and labor effort respectively and $z_{j h k t}$ is the profits remitted to the household by a type $(j, k, h)$ firm. The first order condition determining labor supply is

$$
w_{t}=c_{t}^{\sigma} n_{t}^{\gamma}
$$

and, hence, $\gamma^{-1}$ is the Frisch labor supply elasticity. The first order condition determining consumption is

$$
c_{t}^{-\sigma}=\lambda_{t}
$$

where $\lambda_{t}$ is the multiplier on the household's budget constraint, which serves also to value the firms.

\subsubsection{The Demand Aggregator}

We use the standard Dixit Stiglitz demand aggregator. Thus, $c=\left(\int_{0}^{1}(y(i))^{\frac{\epsilon-1}{\epsilon}} d i\right)^{\frac{\epsilon}{\epsilon-1}}$. 


\subsection{Firms}

There are two aspects of firm specification that warrant discussion. First, we adopt a simple production structure, but we think of it as standing in for some of the elements in the "flexible supply side" model of Dotsey and King [2006]. Second, we discuss the optimal pricing condition given the structure of demand, productivity and adjustment costs.

\subsubsection{Factor demand and marginal cost}

Production is linear in labor, $y(i)=a(i) n(i)$, where $y(i)$ is the output of an individual firm, $a(i)$ is the level of its technology, and $n(i)$ is hours worked at a particular firm.

Hence, real marginal cost, $\psi_{t}$, is given by $\psi_{t}=w_{t} /\left(a_{t} e_{k}\right)$ for a firm that is in microstate $k$ at date t.

\subsubsection{Optimal price-setting}

The adjusting firm sets an optimal price which satisfies the FOC

$$
0=\lambda(s) z_{p}\left(p^{*}, e, s\right)+\beta \eta E\left[\underline{v}_{p}\left(p^{\prime}, e^{\prime}, s^{\prime}\right)\right]
$$

with $p^{\prime}=p^{*} / \pi\left(s^{\prime}\right)$ and the nonadjustment probability being $\eta(p, e, s)=1-\alpha\left(p^{\prime}, e^{\prime}, s^{\prime}\right)$.

The marginal value for a nonadjusting firm is

$$
\underline{v}_{p}(p, e, s)=\lambda(s) z_{p}(p, e, s)+\beta E\left[\eta\left(p^{\prime}, e^{\prime}, s^{\prime}\right) \frac{1}{\pi\left(s^{\prime}\right)} \underline{v}_{p}\left(p^{\prime}, e^{\prime}, s^{\prime}\right)\right]
$$

with $p^{\prime}=p / \pi\left(s^{\prime}\right) .^{2}$

\footnotetext{
${ }^{2}$ Maximizing the "free adjustment value" (5) implies a first order condition,

$$
0=\lambda(\varsigma) z_{p}\left(p^{*}, v, \varsigma\right)+\beta E\left[\frac{1}{\pi\left(\varsigma^{\prime}\right)}\right) v_{p}\left(\frac{p^{*}}{\pi\left(\varsigma^{\prime}\right)}, v^{\prime}, \varsigma^{\prime}, \xi^{\prime}\right)
$$

The value function $v$ takes the form

$$
v(p, v, \varsigma, \xi)=\left\{\begin{array}{cc}
\underline{v}(p, v, \varsigma) & \text { if } \xi \geq \bar{\xi}(p, v, \varsigma) \\
{\left[v^{o}(v, \varsigma)-\lambda(\varsigma) w(\varsigma) \xi\right]} & \text { if } \xi \leq \bar{\xi}(p, v, \varsigma)
\end{array}\right\}
$$
}

so that

$$
v_{p}(p, v, \varsigma, \xi)=\left\{\begin{array}{lc}
\underline{v}_{p}(p, v, \varsigma) & \text { if } \xi \geq \bar{\xi}(p, v, \varsigma) \\
0 & \text { if } \xi \leq \bar{\xi}(p, v, \varsigma)
\end{array}\right\} .
$$

Since $\underline{v}_{p}$ does not depend on $\xi$, we can express the FOC as in the text. A similar line of reasoning leads to the condition (14). 


\subsection{The monetary sector and macroeconomic equilibrium}

To close the model, it is necessary to specify the monetary sector and to detail the conditions of macroeconomic equilibrium.

\subsubsection{Demand for money}

We further impose the money demand relationship $M_{t} / P_{t}=c_{t}$. Ultimately, the level of nominal aggregate demand is governed by this relationship along with the central bank's supply of money.

\subsection{Supply of money}

The model is closed by assuming that nominal money supply growth follows an autoregressive process,

$$
\Delta \log \left(M_{t}\right)=\rho \Delta \log \left(M_{t-1}\right)+x_{m t}
$$

where $x_{m t}$ is a mean zero random variable.

\subsection{Macroeconomic equilibrium}

There are three conditions of macroeconomic equilibrium. First, labor supply is equal to labor demand, which is a linear aggregate across all the production input requirements of firms, $\sum_{j} \sum_{h} \sum_{k} \omega_{j h k t} n_{j h k t}$, and also includes labor for price adjustment. Second, consumption must equal output. Third, money demand must equal money supply.

\subsection{Calibration}

Our benchmark settings for the macroeconomic parameters are $\beta=.97^{1 / n}$ where $\mathrm{n}$ is the number of periods in a year. The steady state annualized inflation is $2.5 \%$. Typically, we will be calibrating at a monthly frequency. The coefficient of relative risk aversion, $\sigma=.25$, labor elasticity is 20 , and the demand elasticity is 5 . The potential for any type of endogenous propagation in this type of model is governed by the elasticity of marginal cost with respect to output, and this elasticity must be less than one for the model to generate much in the way of persistence. Thus, low labor supply elasticities or coefficients of relative risk aversion greater than one severely compromise persistence generation in this simple and stark setting. Dotsey and King $(2005,2006)$ explore many features of more sophisticated models that are capable of generating low marginal cost responses to output, but these avenues are unavailable here. 
We view our parameter settings as stand ins for the more realistic persistence generating mechanisms that are present in larger models. However, when nesting other models in this area of research we will apply the parameters consistent with those chosen in the relevant papers. For robustness, we will also look at how setting $\sigma=1$ affects some of our results.

\section{Steady State Analysis}

In this section we compute and analyze a number of steady states, starting with a simple one-state model and progressing to a model that can replicate the distribution of price changes described by Klenow and Kryvtsov (2007). In analyzing how sticky prices impact macroeconomic adjustment, one desires a model that is consistent with the way that individual firms set prices. As it stands, the workhorse time-dependent models of Calvo and Taylor and their various extensions all suffer from significant inconsistencies with the micro data. $^{3}$ Thus, these models can at best be thought of as reduced forms lacking microeconomic foundations. We pursue the line of investigation initiated by Golosov and Lucas (2008) and Midrigan (2006) by disciplining firm pricing decisions in conformance with observations on price data for individual goods. We seek a parameterization of our model that matches the distribution of price changes reported in Klenow and Kryvtsov (2007). The richness of our model also allows for parameterizations that replicate only the moments matched in the preceding two papers. We can perform sensitivity tests indicating what features of those models are at odds with the data and the consequences that entails for their results. Thus, we are able to incorporate the preceding literature, which serves as a building block for our analysis, into our general model structure.

\subsection{Learning about the stationary distribution}

We are interested in learning about the nature of price adjustment in the stationary distribution for three reasons. First, we are interested in learning about the effects of price stickiness on consumption, labor, and output in a setting in which price-stickiness has potential real consequences even in steady state. Second, the stationary distribution should be a guide to the average pattern of micro price adjustment, so that it can be compared to the results of existing empirical studies of micro-price adjustment and also serve to guide future empirical studies. Third, the pattern of price adjustment is important for aggregate dynamics in response to shocks, both in terms of the pattern of average "lag weights" in the

\footnotetext{
${ }^{3}$ For a detailed investigation of the failures of many of the common New Keynesian pricing models see Alvarez (2007).
} 
pricing block and in terms of understanding the incentives that firms have to alter the timing of price adjustment in response to shocks. In what follows we will be primarily concerned with the distribution of price changes, individual firm hazard functions, and aggregate hazard functions. We will also report a number of key model moments that describe important features of the pricing distribution and that have served in the calibration of various models in the literature. Specifically, we will look at the average and median durations of prices (adur and mdur), the fraction of prices that remain unchanged (fsame), the fraction of price changes that are small as defined by Midrigan (fsmall $)^{4}$, the mean of the absolute value of price changes (mnabs $(\mathrm{dp})$ ), the standard deviation of price changes $(\mathrm{sd}(\mathrm{dp}))$, the kurtosis of price changes (kurt(dp)), the mean of positive price changes (mnpos(dp)), and the standard deviation of price levels that were arrived at through a positive price change $(\operatorname{sdpos}(\mathrm{p}))$. The last two moments were used by Golosov and Lucas to calibrate the stochastic process driving idiosyncratic productivity shocks in their model. Also, all prices and changes in prices are expressed in logs and log deviations. The basic calibration, except where indicated, follows the descriptions given in the preceding section.

\subsection{Basic Data Facts on Price Distributions.}

The data facts are taken from Klenow and Kryvtsov (2007) who examine price changes of goods contained in the CPI, Midrigan (2006) who used data from Dominics grocery stores, and Golosov and Lucas (2007) who report statistics derived from data furnished by Klenow and Kryvtsov. Normal prices exhibit a mean duration of 8.6 months. Further, over 70 percent of prices are unchanged in any given month, which indicates that firms are not changing prices according to some indexation scheme. Also, the distribution of price changes includes many small changes, but also a substantial number of large changes. Over $15 \%$ of price changes exceed $15 \%$ in absolute value and approximately $23 \%$ are less than $2.5 \%$ in value. There are more small price changes than large price changes, but the distribution given in KK indicates that there are a significant degree of price changing at all thresholds (and the standard deviation of price changes is quite large. Of equal importance is that the aggregate hazard function is downward sloping for three years, with the exception of a seasonal blip at 12 months. The hazard also drops rather sharply in the first three months and then flattens out. It is these type of facts, many of which are summarized in figure (4) and table 1 , that we are endeavoring to match.

\footnotetext{
${ }^{4}$ Midrigan defines a price change to be small if it the change is less than half the mean absolute value of all price changes.
} 


\subsection{The Benchmark one state model.}

We first look at the benchmark one-state model where the cost of price adjustment distribution is calibrated to produce approximately quadratic hazards. Some basic features of the steady state are described in Figure (5). First it is obvious that the one-state model cannot replicate the basic features of the data. All the price changes are quite small - the standard deviation of price changes is .006, there are no price decreases, and the aggregate hazard rate is upward sloping (Panel D). Another perspective on the upward sloping aggregate hazard comes from Panel C, which plots the price adjustment probability as a function of a firm's relative price. Because there are no idiosyncratic shocks, positive inflation means a firm's highest relative price always occurs in the period of adjustment. As the firm's relative price falls over time with inflation, its probability of adjustment increases. When we add firm-level productivity shocks below, unexpected increases in productivity will create situations where firms wish to decrease their price, and where the probability of price adjustment rises over time even though a firm's relative price depreciates with inflation.

It is features such as the increasing hazard and lack of price decreases for which the initial DKW model was criticized as being inconsistent with the data. In what follows, we shall show how enriching the model with progressively more heterogeneity can overcome these initial criticisms and generate model data that is broadly consistent with data on actual pricing.

\subsection{Adding Idiosyncratic Technology Shocks}

We now begin to explore the effects of adding firm specific heterogeneity on the steady state price distribution. To start we consider the case of two states. Firms in state one draw a technology shock of .92, while those in state two draw a technology shock of 1.08. The transition probabilities are symmetric with each firm having an $80 \%$ chance of remaining in the same state and a $20 \%$ chance of transitioning into the alternate state. These parameter choices allow the two-state model to be roughly consistent with mean of absolute price changes. The maximum fixed cost is adjusted to match the average duration of normal price changes found by Klenow and Kryvtsov (2007). Other than that, all the parameters are identical with the one state example just considered. Now, the standard deviation of price changes is 0.112 , which is roughly twenty times what was found in the one state example and matches the actual volatility in price changes. The aggregate hazard, although initially slightly upward sloping has a significant downward sloping part even though the hazards in each individual state are upward sloping (see Figure (6). We shall return to the effects of 
A. Hazard Rates

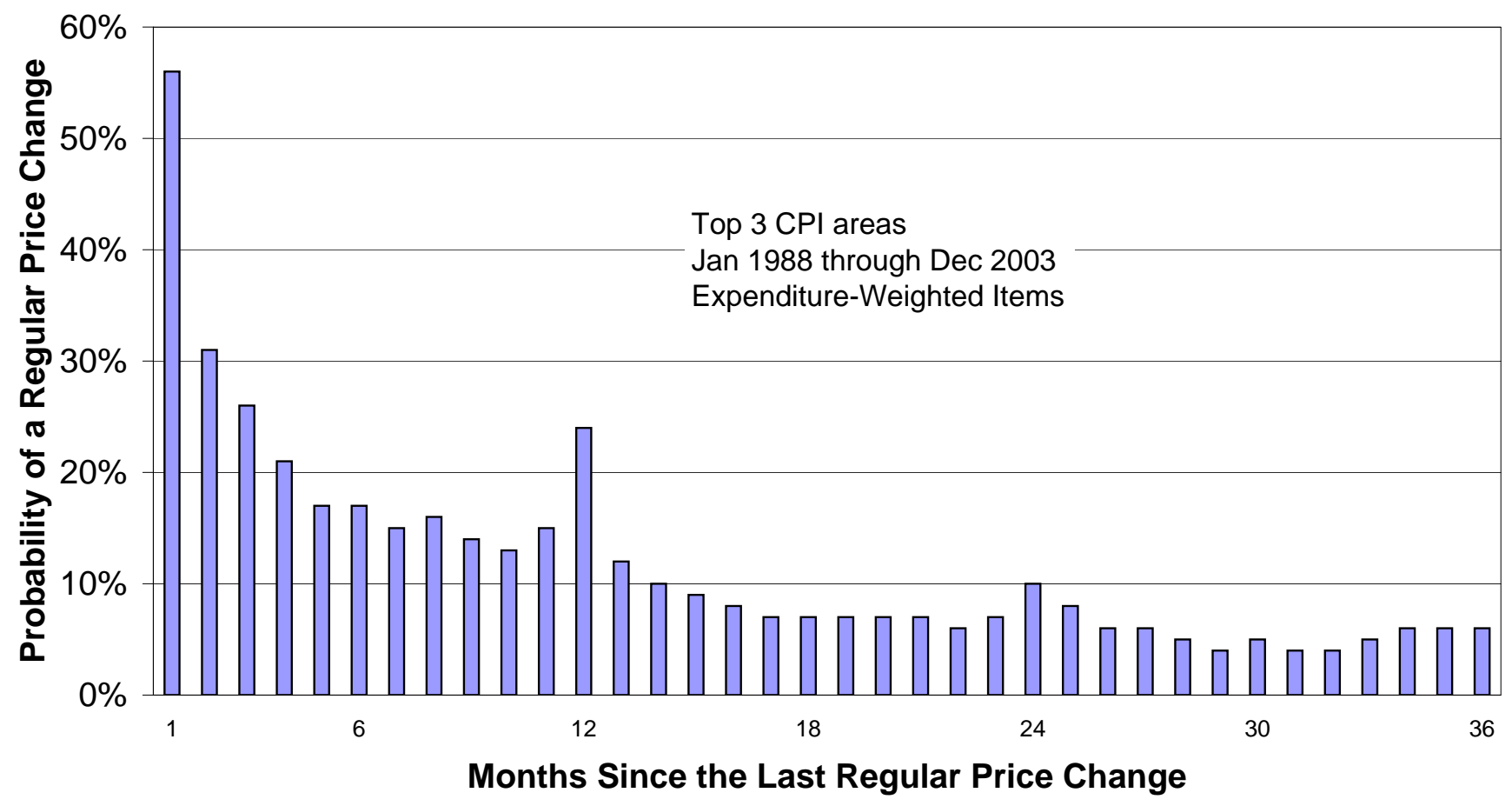

B. Distribution of Regular Price Changes

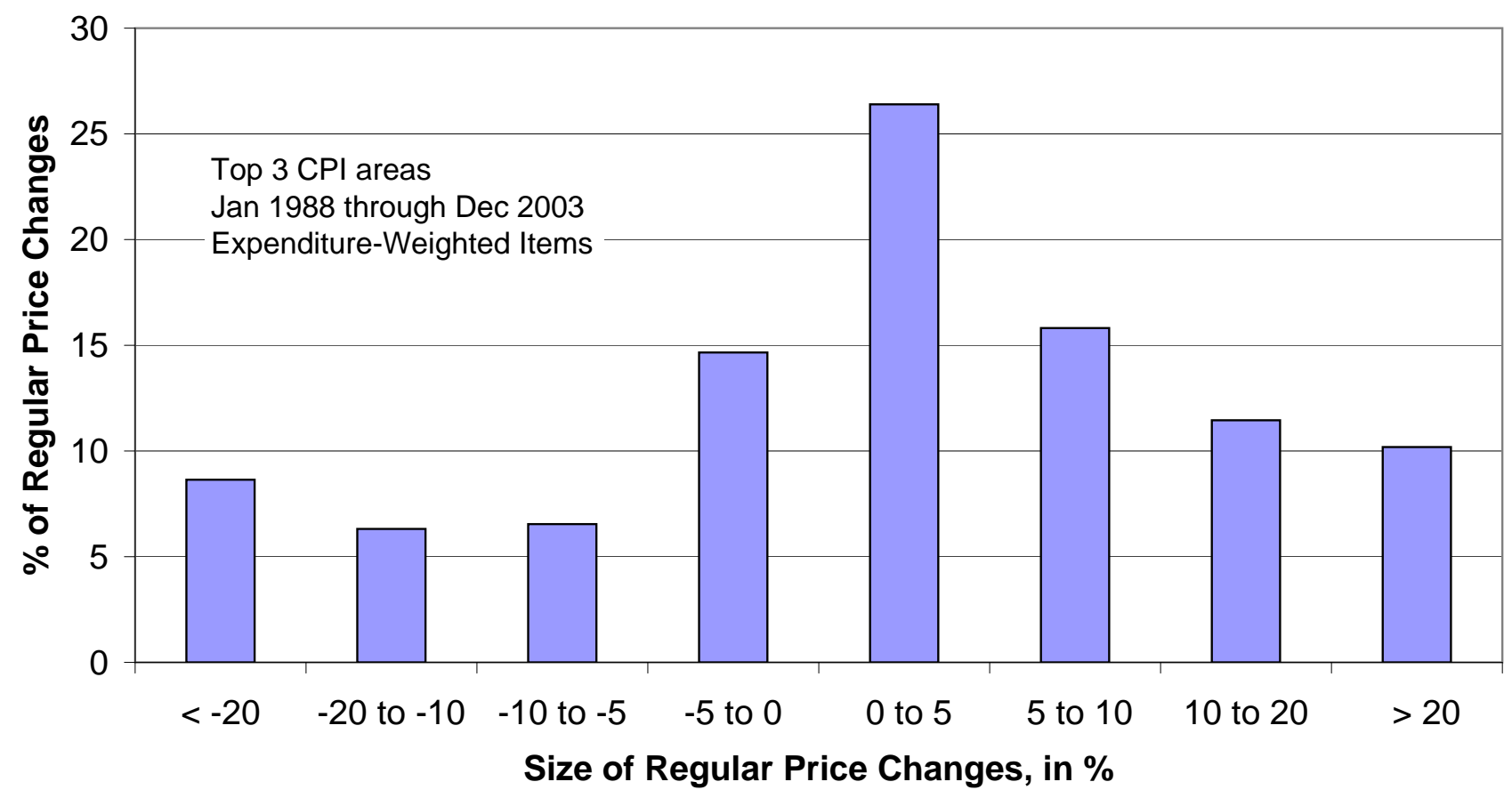




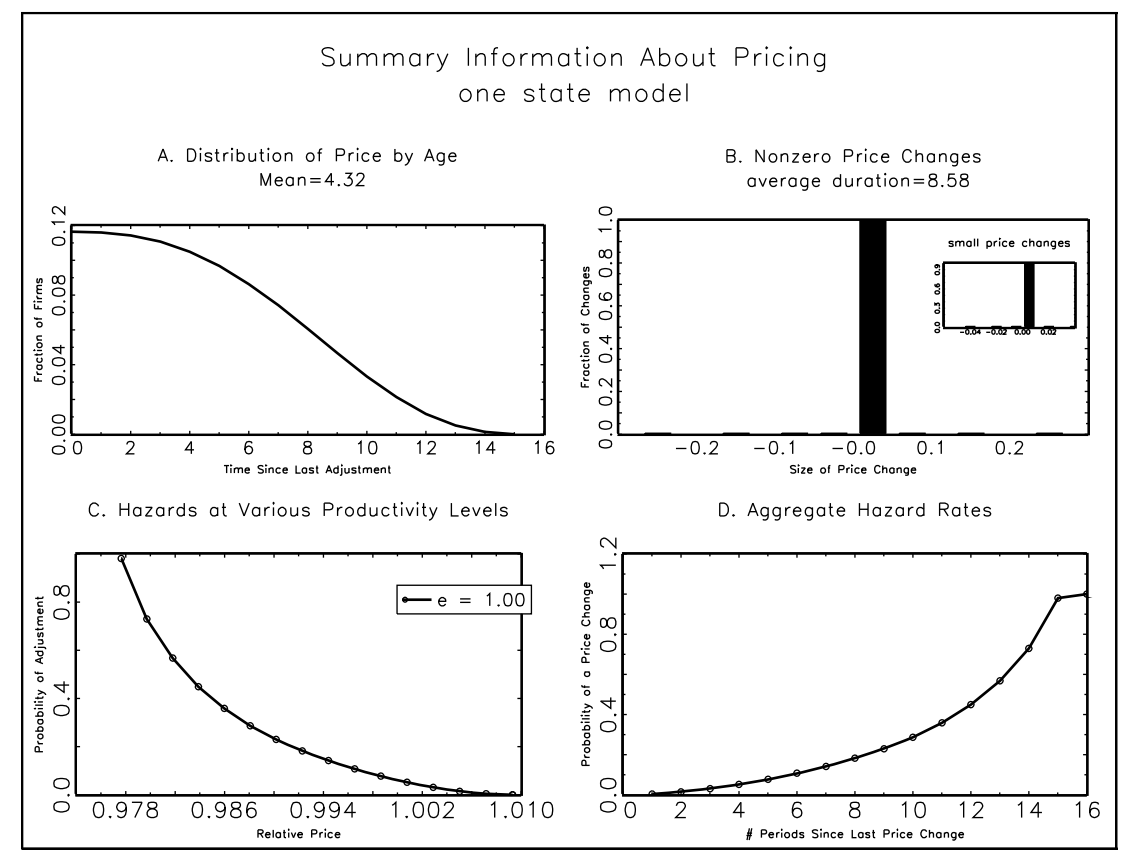

Figure 5:

heterogeneity on the aggregate hazard in a moment. Also, the fraction of firms that maintain the same price is 0.88 , which is somewhat higher than that found in the data. Also, with respect to the magnitude of price changes (Panel b), there is now a significant proportion of both relatively big and relatively small price changes. However, as shown in the inset of Panel b, all the small price changes are quite small. They are less than one percent in absolute value.

Further, with this parameterization there are now firms that do not change their price for over 8 years, although the proportion of such firms is quite small. ${ }^{5}$ The reason for this can be seen by looking at the state specific hazards (panel c ). A firm that initially had a low productivity shock and as a result charged a relatively high price would see its price erode and it would move to the left on the right most hazard. If before its probability of resetting got high, it transited to the high productivity state, it would find itself on the right branch of the left-most hazard, that is the hazard pertaining to the high productivity state. In fact, its probability of changing its price would be declining as its price eroded. If the firm remained in the high productivity state, then it would eventually see its price erode enough that it would reset. However, given the dispersion between the optimal reset prices of the two types of firms, it would take a significant period of time before it was optimal to reset its price with a high probability.

\footnotetext{
${ }^{5}$ The figure only plots the distribution out to 40 months, but some adjustment probabilities remain less than unity out past eight years.
} 


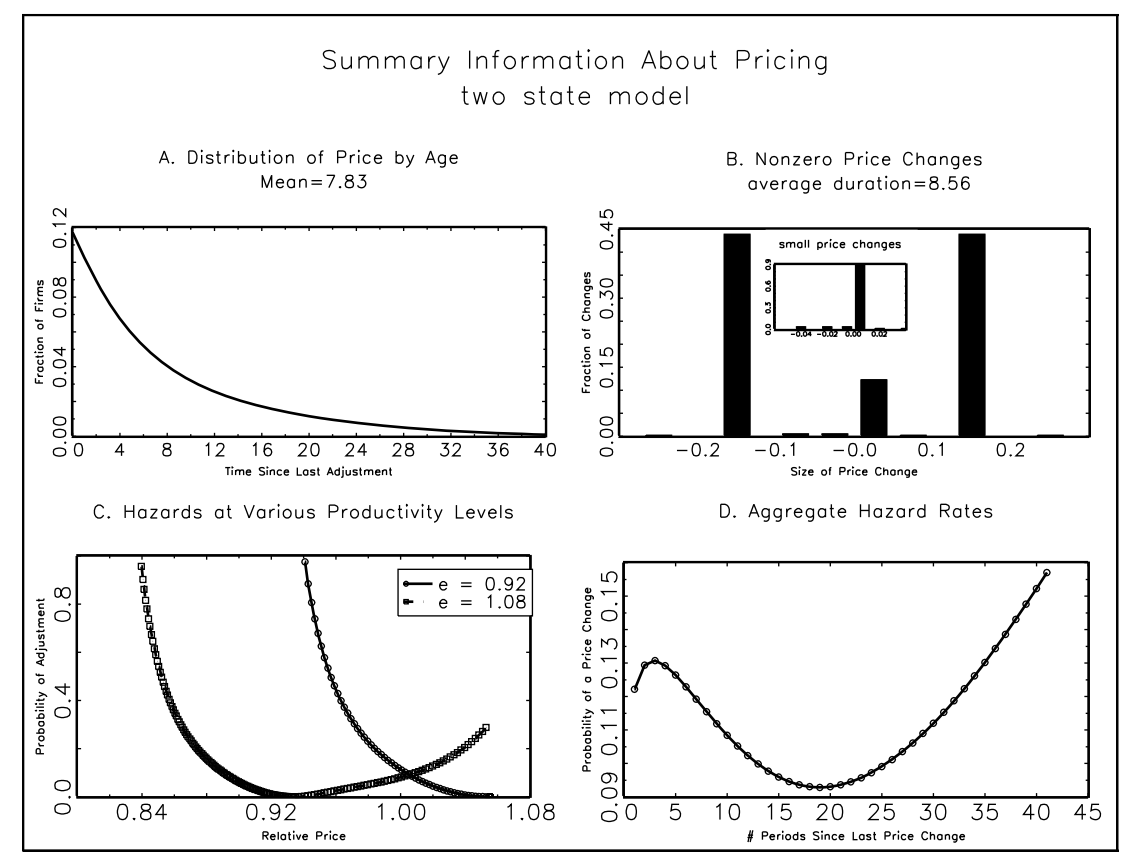

Figure 6:

A notable feature in this example is the wide range over which the aggregate hazard is downward sloping. In order for this to occur there must be many firms with a low hazard, and the fraction of firms with a low hazard must be increasing as we consider older and older prices (i.e.-as we move out along the hazard function). The reasoning is analogous to that which explains a downward sloping aggregate hazards in a model with two types of firms with different, constant adjustment probabilities as in Calvo. Aggregating across these two types of firms gives a downward sloping hazard even though the hazard rates are constant for each type. As the age of a price progresses, the fraction of firms who have not adjusted is increasingly dominated by those with the lower hazard - implying a downward sloping aggregate hazard rate. In the limit the aggregate hazard approaches that of the low hazard type firms. In this example, the proportion of firms with a low hazard is increasing in age over a significant range and aggregation implies a downward sloping hazard.

One can see this by examining the two left panels of Figure (7). where we graph the state specific hazards as functions of relative prices and the weights placed on firms with those particular hazards. First examine the upper left figure, which gives the hazard rates for the various types of firms. The age of a price is represented by the number of symbols one must count to the right in order to reach the firm's reset price (at which point the hazard is zero). For example the downward sloping line with circles depicts the upward sloping hazard (upward in age, that is) of low productivity firms who remain low productivity firms, and the fourth circle to the left of the reset price is the relative price of a firm who reset 
its price while in the low productivity state four periods ago and is in the low productivity state at that time. The upward sloping squares indicate the downward sloping (age) hazards of firms who were low productivity but switch to being high productivity. This hazard is downward sloping because over time inflation erodes the relative price and makes it closer to the optimal price of resetting high productivity firms. If there are enough of these type of firms, then the aggregate hazard will be downward sloping.

Thus, one needs to know the evolution of the fraction of firms over time. This evolution is given in the bottom left panel, where again the time elapsed since prices were reset is depicted by the distance from the reset price. As shown in the bottom left panel, the fraction of firms that transit from the low to high productivity state $\theta_{j, 1,2}$ is increasing over time eventually becoming more than half the firms. Because these are the firms experience a falling hazard rate and their share is rising the aggregate hazard is downward sloping.

When the idiosyncratic productivity shocks are i.i.d., the downward sloping portion of the hazard function for the low to high transiting firms is smaller. The distribution of optimal prices is much narrower, so the fraction of firms that are on the downward sloping portion never gets large enough to offset the upward sloping hazards faced by most firms. Thus, a combination of relatively large persistence and dispersion in productivity shocks is required in order to generate a downward sloping aggregate hazard.

The relationship that price dispersion and persistence have on the shape of the aggregate hazard is shown in the three dimensions in Figure (8). Look first at the right-most slice of the right-most figure; it represents the aggregate hazard function for a model with zero dispersion of the idiosyncratic shocks - that is, a model without idiosyncratic shocks. The hazard function is everywhere upward sloping, as are the hazards displayed in Dotsey, King and Wolman (1999) for a model without idiosyncratic shocks. With zero dispersion all firms have the same optimal price. Constant, nonzero inflation means that age moves all firms uniformly away from their optimal price, raising the adjustment probability for all firms. As the dispersion of idiosyncratic shocks increases (moving left along the axis labeled "dispersion") the successive slices become flatter and for dispersion around 0.7 the hazards begin to have downward sloping portions; it is in this region that there is a large fraction of firms transiting from low to high productivity and then letting their relative price depreciate as described above. For very high degrees of dispersion the hazards again become upward sloping; in this region reset prices vary greatly across productivity levels, so changes in productivity inevitably involve changes in price

The left-most figure in Figure (8) illustrates how the aggregate hazard function varies with the idiosyncratic shock's persistence. Without persistence - the right-most slice of the figure, the hazard is everywhere upward sloping. In this case reset prices are relatively insensitive 


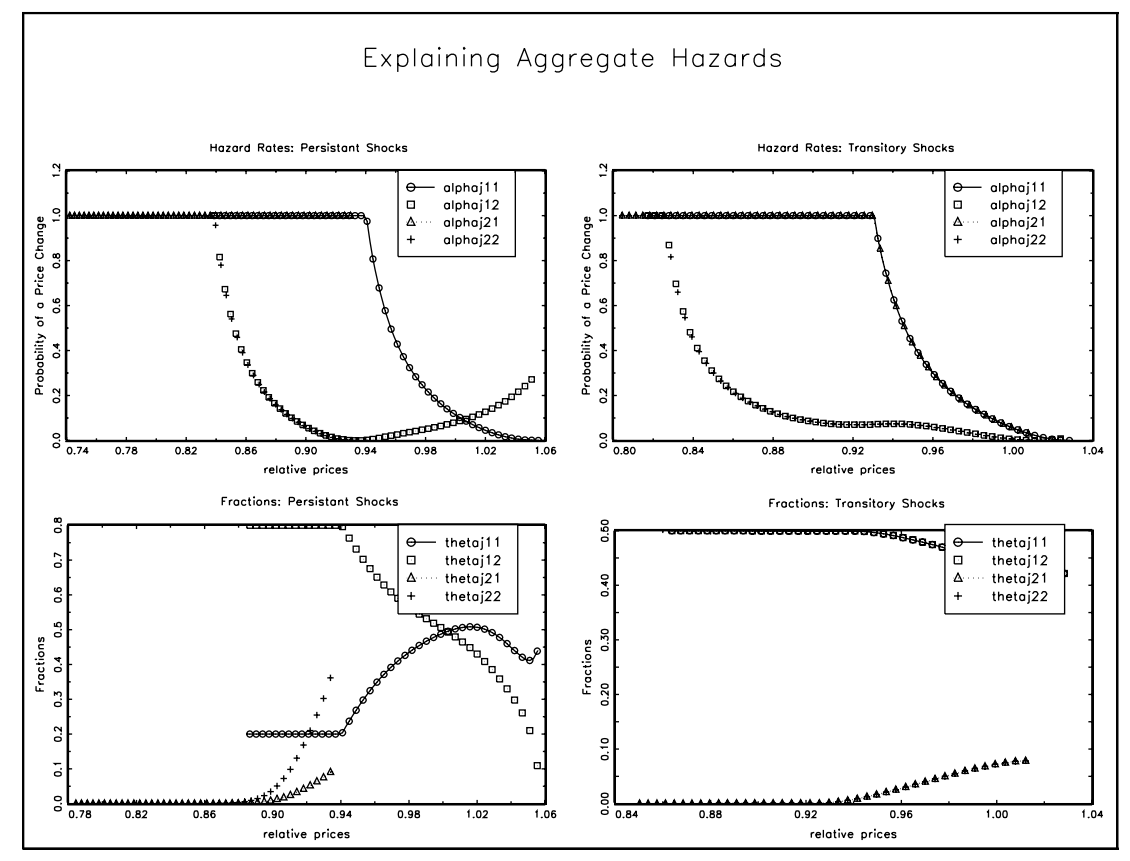

Figure 7:

to productivity, because firms' future productivity levels are independent of productivity at the time they set their prices. As persistence increases the reset prices spread apart, creating the condition described above under which hazards may slope down. For very high degrees of persistence, transitions across states are rare, so that although they can lead to decreasing hazards for certain productivity trajectories, there are too few firms with such trajectories for the aggregate hazard to slope down.

\subsection{Adding an Additional State}

We now look at the effects of adding an additional state. Here the firm specific technology shocks take on values of .92, 1.0, and 1.08 and the markov transitions are governed by $\left[\begin{array}{ccc}.8 & .2 & 0 \\ .1 & .8 & .1 \\ 0 & .2 & .8\end{array}\right]$. Adding a third state yields a richer distribution of price changes (see Figure (9). There are now relatively more small price changes than in the two-state example and less large price changes. However, because there is now a chance of being in an intermediate state, the overall dispersion of optimal prices is somewhat smaller resulting in an aggregate hazard that is upward sloping nearly everywhere. 


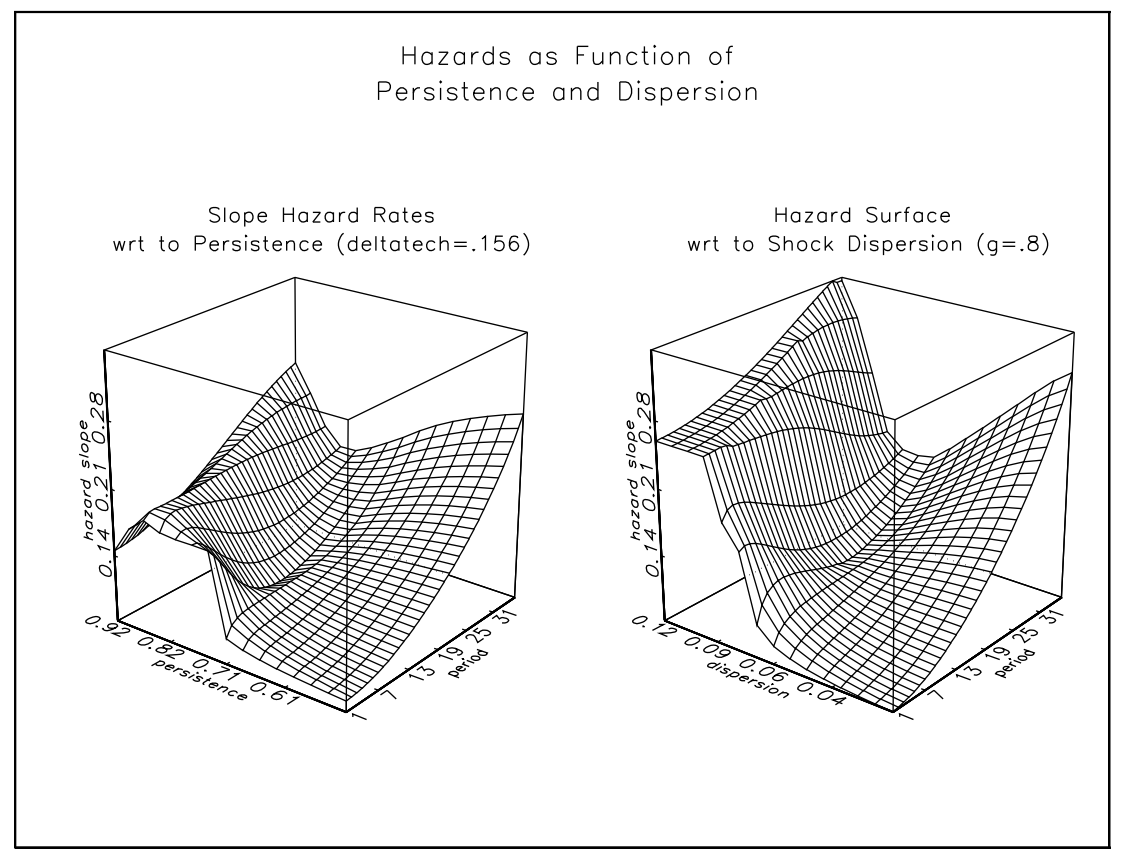

Figure 8:

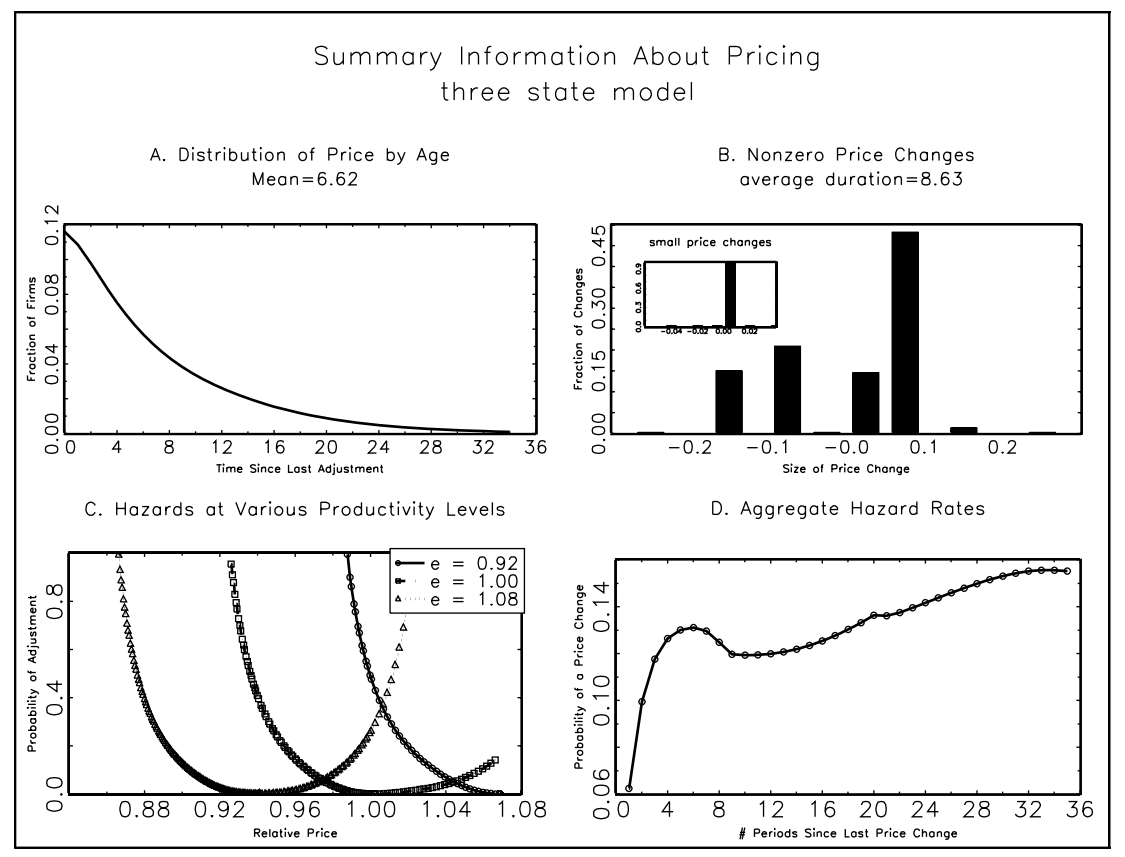

Figure 9: 


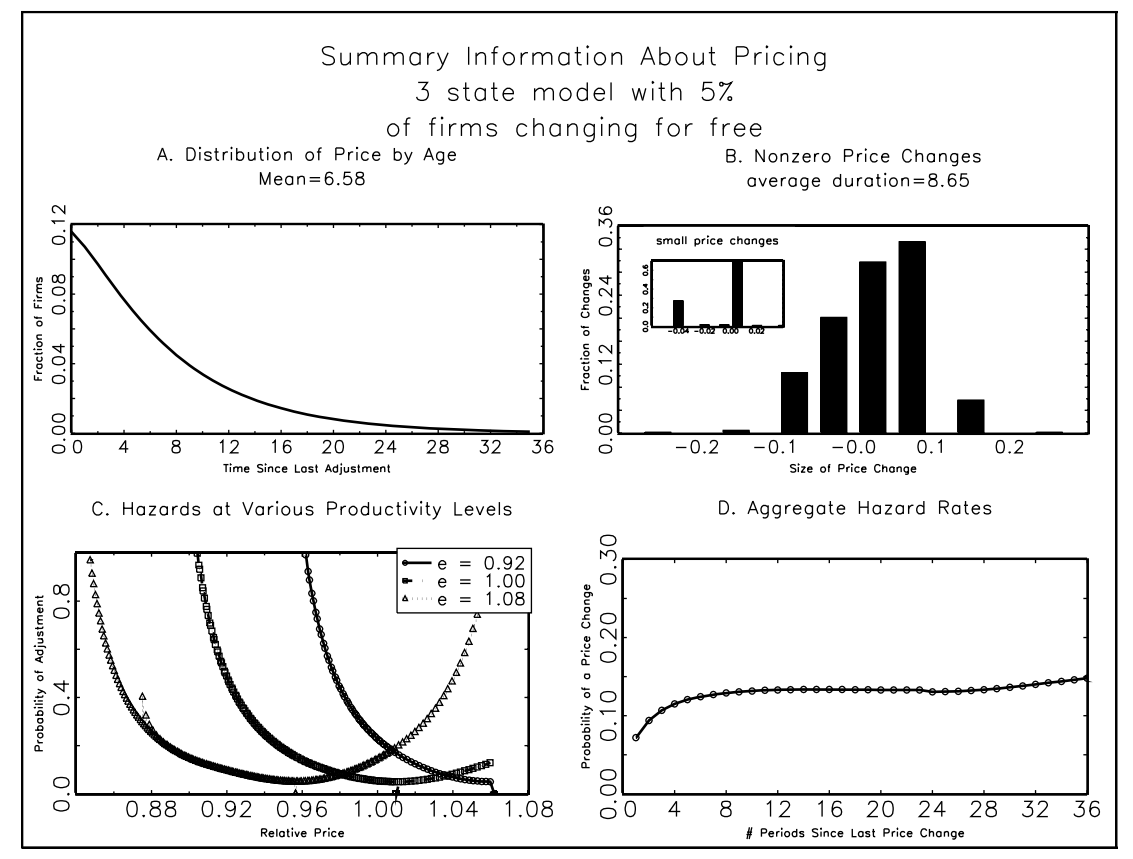

Figure 10:

\subsubsection{Allowing a fraction of firms zero cost of changing prices.}

A notable problem with all the examples so far is that there are not enough small price changes. Anticipating one of the model features we will use in matching the distribution of price changes reported in Klenow and Kryvtsov (2007), we allow a small fraction (here 5\%) of firms to change prices at no cost. As can be seen in figure 10, the overall distribution of price changes is moving toward the distribution displayed in figure (10). This result is also consistent with the insight of Midrigan (2006), that some price changes need to be relatively costless in order for an SDP model to match the large fraction of small price changes.

\subsubsection{Allowing flexible prices.}

To analyze how price rigidities affect the distribution of price changes, keeping all other parameters the same as in the previous two examples, we also look at the case where all prices are flexible. The resulting distribution of prices is displayed below.

As is evident, most price changes are small because the productivity process for each firm is persistent. There are much less price changes of intermediate size, because firms relative prices never erode as they do when prices remain fixed for significant periods of time.

\section{Matching Various Models in the Literature}

Having gained some intuition concerning features of heterogeneity that contribute to the 


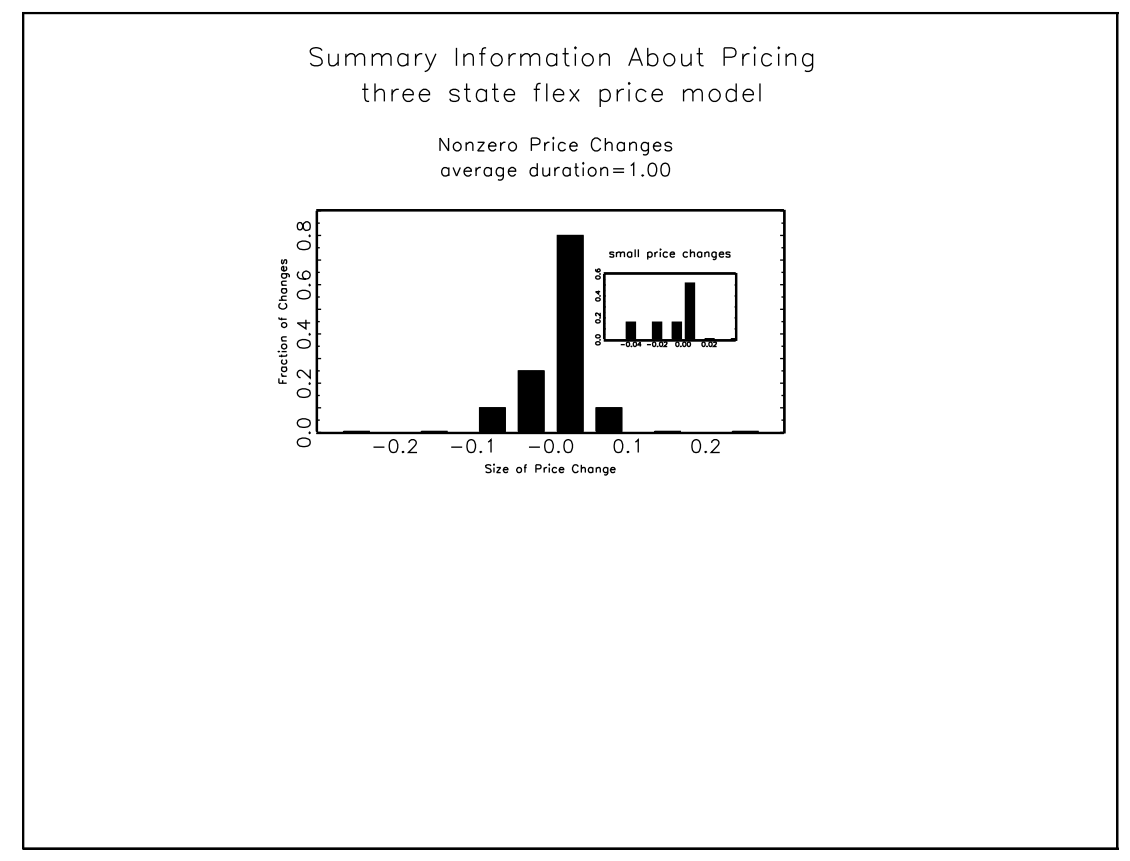

Figure 11:

overall shape and moments of the price change distribution, we now proceed to use our model to replicate the results found in Golosov and Lucas, and Midrigan, and then match the distributions reported in Klenow and Kryvtsov. In doing so we will use the calibrations of the respective papers and then estimate via simulated annealing the parameters of the idiosyncratic technology process and the maximal cost of price adjustment needed to replicate the moments that these authors match. Further, we use Tauchen style routines to estimate the support of the shocks and the markov transition matrices that conform with the distributions of the shocks in the various models. In addition, to conform with the two models under consideration, we use different underlying distributions of the technology shocks for each exercise. In the Golosov-Lucas exercise the shocks are distributed normally, while in the Midrigan exercise they are distributed compound beta

\section{The Model of Golosov and Lucas}

For the Golosov and Lucas model we set the CRRA parameter in our utility function to 2 , and labor elasticity is set at 100 , which quantitatively closely approximates the infinite labor supply elasticity used in their model. Steady state hours are .37 and the demand elasticity is 7. Golosov and Lucas use a single value for the fixed cost of changing prices. To approximate that feature in our model,we parameterize that distribution so that almost all the mass of the distribution is at a single value. We check to see if the approximation is reasonable by examining the individual hazards, $\alpha_{j, h, k}$ to see that they are all close to 


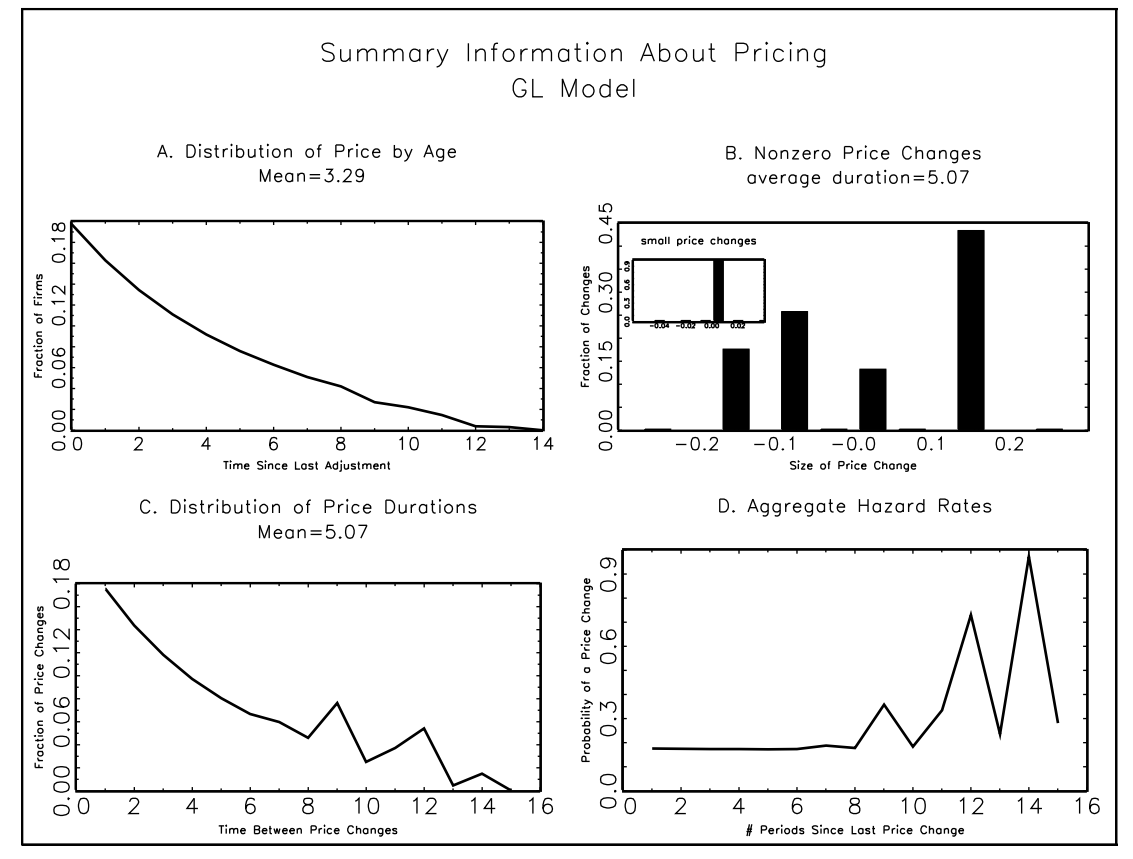

Figure 12:

zero or one. Further, the underlying idiosyncratic technology shock distribution is normal. We approximate this distribution using 5 states or values for the firm specific technology shocks. Better approximations can be obtained with more states, but we are forced to be parsimonious in order to limit the size of the model. If there are too many states, the model becomes so big that the dynamic system cannot be solved.

We then estimate the standard deviation and autocorrelation of the idiosyncratic technology process as well as the maximal fixed cost of price adjustment that allows the model to best match the three moments of the pricing data that Golosov and Lucas match, namely the mean of positive price changes, the distribution of prices of firms who raised their price, and the fraction of firms that change their price, which are reported by GL to be 0.095, 0.087, and 0.78 respectively. From Table 1, one can see that we replicate these moments almost exactly. The parameter estimates in our model that allow us to match these moments are a standard deviation of the technology shock process of .0365, an autocorrelation of .855, and a maximal fixed cost of .0013, which is less than the .0025 used by GL. One also notes that this parameterization produces too few small price adjustments and the distribution of price changes, although an improvement on models lacking heterogeneity, does not replicate the distribution of price changes in the KK data. Further, there is not enough endogenous persistence in price setting and the aggregate hazard function is upward sloping. 


\subsection{The Model of Midrigan.}

Midrigan's model is fairly complex and involves the setting of multiple prices. Midrigan observes that in Dominic's supermarket data prices of goods that are alike are changed with a good deal of synchronization. For example, when the price of one brand of beer is changed, the prices on other brands of beer are likely to be changed even if that involves small price changes for some of those brands. To capture that type of behavior, Midrigan populates his economy with firms that jointly produce two varieties of goods, but are subject to the same fixed cost of changing prices whether one or both prices are changed. This feature of his model allows him to replicate the large fraction of small price changes in the data. The specification of idiosyncratic technology shocks is also a bit more complicated in his model, and takes the form a compound beta distribution. Specifically,

$$
z_{t}=\left\{\begin{array}{c}
-b_{t} z_{\max } \text { with probability }=1 / 2 \\
b_{t} z_{\max } \text { with probability }=1 / 2
\end{array}\right.
$$

where the $b^{\prime} s$ are drawn from a beta distribution. We approximate his model by allowing a fraction of firms in our model to change prices costlessly each period, which helps us match the frequency of small price changes. We parameterize our idiosyncratic technology shocks as follows. First we take a discrete approximation of a compound beta distribution, allowing the simulated annealing routine to pick the two parameters of the compound beta distribution along with the serial correlation of the shocks. The support of the distribution is also scaled, which is equivalent to scaling the variance of the shocks. We also allow the routine to find the maximal fixed cost of price adjustment and the fraction of firms that are allowed a free price change each period. These 5 parameters are chosen to match the mean of absolute price changes (.09), the average duration between price changes (4.5 months), the standard deviation of price changes (.12), the kurtosis of the price change distribution (1.5), and the fraction of small price changes (.30) as defined in Midrigan (2006).

We depart from the single fixed cost representation of our price-changing cost distribution for the following reason. When working with a single fixed cost, we found that the best match to the above statistics involved a significant fraction of firms that changed prices for free and a rather high fixed cost of changing prices. The end result was that almost all the price changing was costless, and the model took on the properties of a time-dependent Calvo model. While that representation was consistent with the sample moments, it violated an important feature of Midrigan's model, namely that firms do pay to change prices. To get around the counterfactual of the single fixed cost representation, we used the approximately 
quadratic price-changing distribution shown if figure 1. Even so, under that representation, of the $22.4 \%$ of firms who change prices each period $17.8 \%$ do so for free.

It is not obviously what an exact match would be without more detailed information concerning the distribution of price changes. In Midrigan's model, 50\% of firms changing prices for free, but these firms are not randomly chosen. They are firms that end up making relatively small price changes. In our model, the free adjustment cost hits firms randomly. In a specification where individual hazards are constant or rising there are less firms in the population that need to make relatively large price changes, so by using a price setting cost specification with increasing hazards our setup will also generate a greater fraction of relatively small price changes among those drawing the zero fixed cost. Exactly what specification of price adjustment costs would accurately approximate Midrigan's model would require matching a more detailed representation of his models distribution of price changes. .

The remainder of the parameterization is straightforward. The utility of consumption is logarithmic and labor supply is infinitely elastic, so we set the elasticity in our framework to 100 . Agents work $1 / 3$ of their time and the elasticity of demand is 3 . Inflation is $2.5 \%$ annually.

The resulting values for the parameters of the beta distribution were 3.36 and 1.68. The standard deviation and autocorrelation of the process were .109 and .26 . The fraction of firms that get a free price change was .178 and the maximal fixed cost is .066. Using these parameters, our model produces steady state values for the average duration of 4.44, a mean absolute price change of .087 and a standard deviation of .121. The probability of small price changes is .34 and the kurtosis is 1.52 indicating a close approximation to the moments in Midrigan's data. From Figure 13, one sees that the model also produces a rich distribution of price changes that is not too dissimilar from that given by actual data using price changes in the CPI. The fraction of firms charging the same price using the Midrigan calibration is .78 and thus very close to what is found in the data as well. Also, the hazard function is quite flat.

\subsection{Matching the Klenow and Kryvtsov Distribution}

The final model is one that goes full bore and tries to replicate the distribution of price changes as well as the average duration that are reported in Klenow and Kryvtsov (2007). The results are displayed in Figure (14), and the equality of the distributions cannot be rejected by a Kolmogorov-Smirnov test at the $5 \%$ critical value. Also, of note is the sharp downward drop in the aggregate hazard over the first two months and the extreme flatness of the succeeding16 months. Thus, for a period up to almost two years, the aggregate hazard 


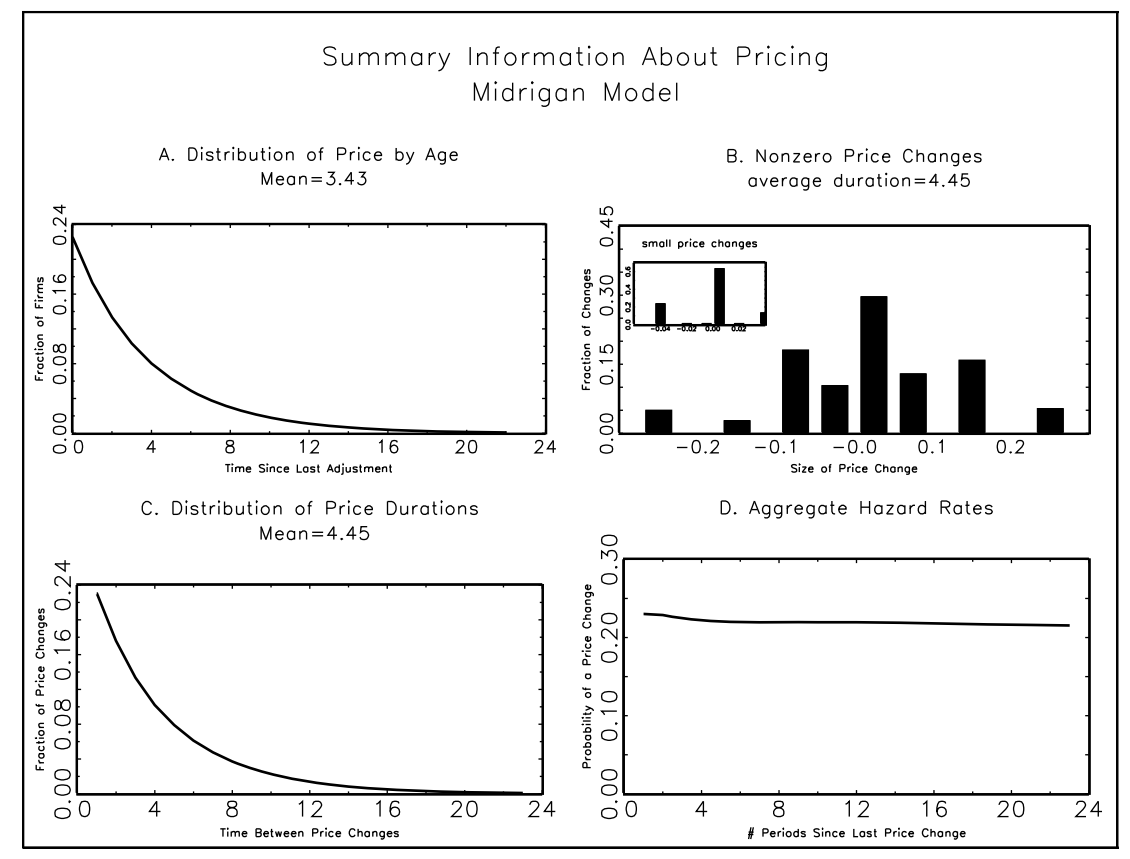

Figure 13:

displays a reasonable resemblance to what Klenow and Kryvtsov (2007) find in the data. In order to achieve this match we must mix two distributions. The interior of the distribution for technology disturbances is governed by a beta distribution, The important parameters governing the distribution of technology shocks are the parameters of the beta distribution $(1.10, .1 .23)$, an autocorrelation of the technology shocks of 0.90 and a standard deviation of technology shocks of 0.084 distributed over 5 evenly spaced grid points. In addition, to match the number of very small price changes we allow $4.9 \%$ of firms to draw a zero cost of changing their price. To match the density of large price changes we mix this beta distribution with a distribution of extreme technology shocks that have a probability of being reached $\zeta=7.5 \%$ of the time from the interior distribution. When an extreme state is realized, in the next period the state returns to the interior with certainty. If $\Phi$ is the markov transition matrix for the interior states and $\phi$ is the steady state distribution of firms in each micro-state, then the markov transition matrix for the mixing distribution is given by

$$
G=\left[\begin{array}{ccc}
0 & \phi & 0 \\
\zeta * \mathbf{1} & (1-2 \zeta) \Phi & \zeta * \mathbf{1} \\
0 & \phi & 0
\end{array}\right] .
$$

The standard deviation in firm specific technology shocks implies that the the inner grid of shocks ranges from 0.89 to 1.11. Further, the extreme technology shocks take on values of 


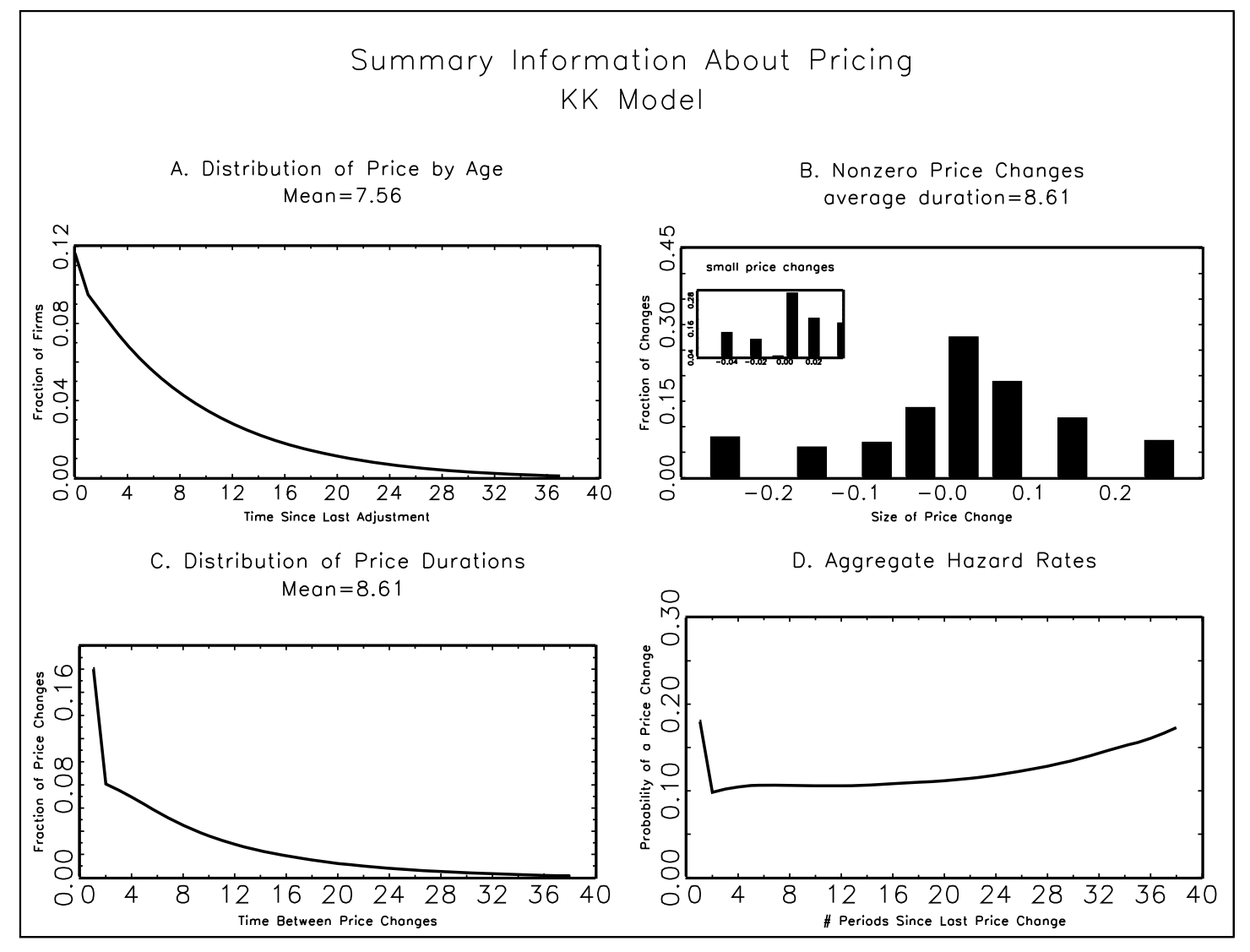

Figure 14:

0.81 and 1.23. Finally, even though most firms pay a fixed cost to change price only $0.35 \%$ of labor is used in changing prices. Thus, it does not take very much in the way of menu costs for the steady state of our model to match many of the rich features of price changing found in the data.

Figure (15) illustrates some of the effects of steady state inflation in our Klenow-Kryvtsov model. To produce the figure, we hold fixed all parameters except the inflation rate, which is varied in small increments between one percent and 36 percent annually. Increasing the steady-state inflation rate creates a greater incentive for firms to adjust their prices, on average. ${ }^{6}$ The downward sloping lines, measured on the left axis, represent the average duration and average age of prices, in months. Average duration falls from more than nine months at one percent inflation to around seven months at ten percent inflation, to less than five months at 36 percent inflation. Average age falls from more than eight months at one percent inflation to around five months at ten percent inflation, to less than three months

\footnotetext{
${ }^{6}$ Conditional on some transitions from low to high productivity, higher inflation may decrease the amount of adjustment - the real price depreciation from inflation may bring a firm's price closer to optimal.
} 
at 36 percent inflation. The upward sloping line, measured on the right axis, represents the fraction of firms adjusting their price in any period. At one percent inflation just 10.9 percent of firms adjust their price in a period; this number rises to 14.6 percent at ten percent inflation, and to above twenty percent at 36 percent inflation. Although these measures of price flexibility respond noticeably to inflation over the range in the figure, at 36 percent inflation price adjustment is still markedly below what it would be without fixed costs of adjustment. Without price adjustment costs, the frequency of price adjustment is determined entirely by the productivity process. For the productivity process in our Klenow-Kryvtsov model, without adjustment costs 51 percent of firms would adjust their price in any month, and the average duration of a price would be about 2.2 months. In order for the calibrated Klenow-Kryvtsov model with adjustment costs to achieve that degree of price flexibility, inflation would have to be increased far above 36 percent.

\subsection{Summarizing}

The basic steady state statistics produced by the various examples in this section are given in Table 2. One sees that in order to generate both sufficient volatility in price changes along with a significant fraction of firms making only small price changes requires a rich "microstate" environment. Further, it is important that a significant fraction of firms face low costs of price adjustment and that there is a meaningful spread in the productivity shocks It is also important that firms find themselves in situations where they are willing to make fairly small price changes, if the detailed data on price changing is to be matched. While the steady state characteristics of the price changing data is interesting in itself, we now turn to the implications that adding heterogeneity has for dynamics. 


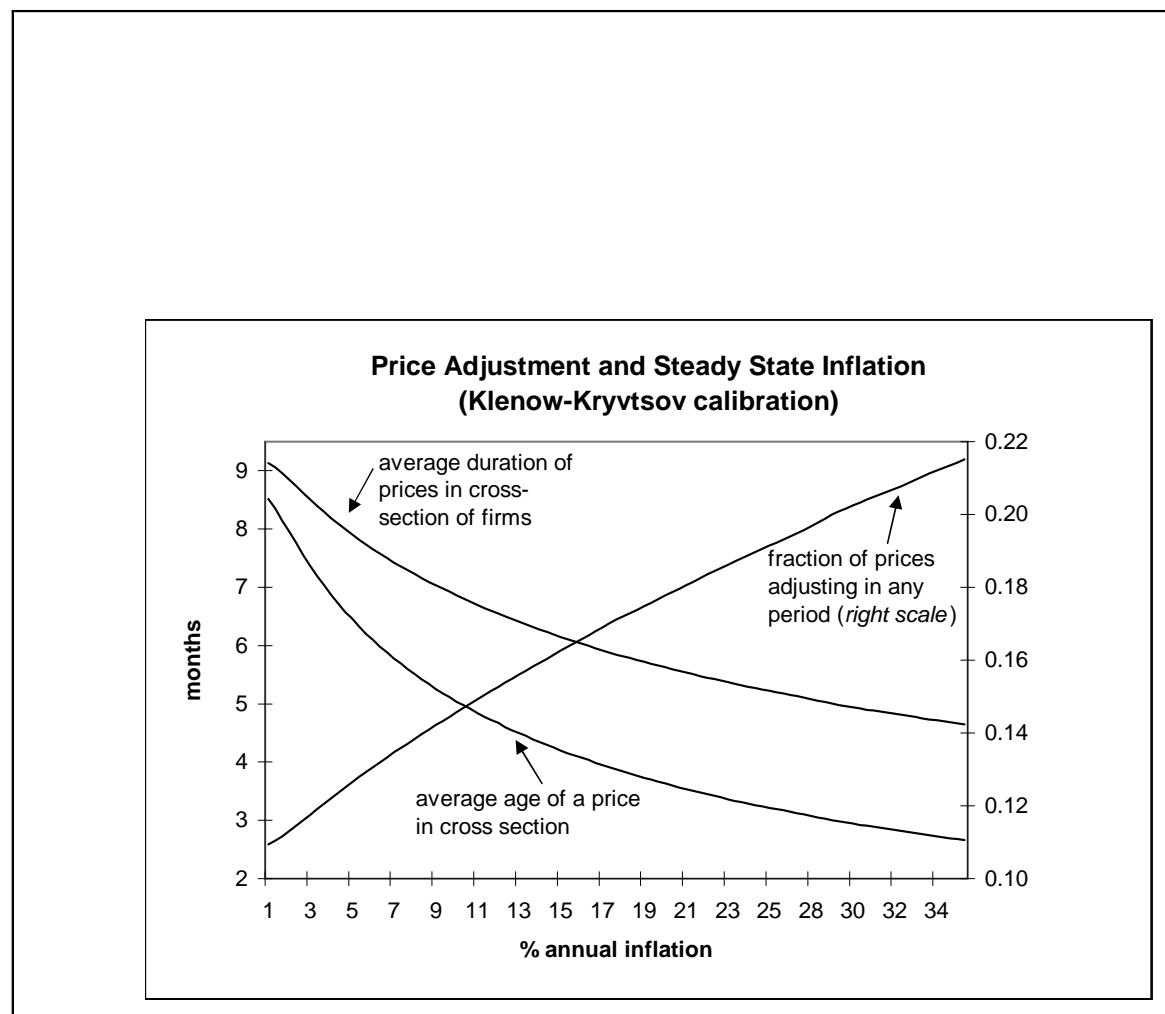

Figure 15: Varying Inflation in KK model 


\begin{tabular}{|c|c|c|c|c|c|c|c|c|}
\hline \multirow[b]{3}{*}{ statist } & \multicolumn{8}{|c|}{ Table 2} \\
\hline & data & 1state & 2state & 3state & $\begin{array}{l}3 \text { state } \\
\text { zero cost }\end{array}$ & GL & $\mathrm{M}$ & KK \\
\hline & & & & & & & & \\
\hline adur & $8.6(4.5)$ & 8.58 & 8.56 & 8.63 & 8.56 & 5.06 & 4.44 & 8.57 \\
\hline mdur & 7.2 & 9.0 & 6.0 & 6.0 & 7.0 & 4.0 & 3.0 & 6.0 \\
\hline fsame & .73 & .88 & .88 & .88 & .88 & .80 & .77 & .88 \\
\hline fsmall & $(.30)$ & .10 & .084 & .09 & .32 & .13 & .34 & .37 \\
\hline mnabs(dp) & $.11(.09)$ & .018 & .109 & .07 & .043 & .095 & .087 & .09 \\
\hline $\operatorname{sd}(d p)$ & $.0119 ?(.12)$ & .006 & .11 & .072 & .049 & .099 & .12 & .117 \\
\hline $\operatorname{mnpos}(\mathrm{dp})$ & $.095^{*}$ & .018 & .11 & .069 & .042 & .093 & .075 & .083 \\
\hline $\operatorname{sdpos}(p)$ & $.087^{*}$ & .000 & .019 & .034 & .031 & .087 & .052 & .029 \\
\hline $\operatorname{kurt}(\mathrm{dp})$ & (1.5) & -.62 & -1.83 & -1.17 & -.46 & -1.83 & 1.52 & .20 \\
\hline
\end{tabular}

Also the GL

model calibration is to hit fsame $=.79$. 


\section{Dynamics}

In exploring the dynamic implications that heterogeneity and state-dependent pricing have for aggregate economic responses to money supply shocks, we will follow much the same plan as in the preceding section; progressing from a simple one state example and concluding with the dynamic responses of a model economy calibrated to the Klenow and Kryvtsov (2007) data. This progression will shed light on the interaction between the various features of heterogeneity and aggregate dynamics.

\subsection{One state model}

We begin with the one-state model used in Dotsey and King (2005). It is obvious that the model's dynamics are quite unusual when viewed from the perspective of most published estimated aggregate responses to monetary shocks. The impulse responses are extremely oscillatory due to the fact that the benchmark parameter settings and the approximately quadratic hazards generate a good deal of synchronization in the pricing decisions of firms. Initially only a few firms adjust prices and prices rise less than the money stock and output rises. Subsequently lots of firms simultaneously adjust prices, the price level rises rapidly and output falls. With most firms having adjusted prices together, there is then less price adjustment than in steady state, the price falls below the money stock and output rises. This oscillatory behavior eventually dies down and the economy returns to steady state. The rate of convergence is faster as the coefficient of risk aversion is increased from its benchmark value of 0.25 .

\subsection{Two state model}

Given the somewhat anomalous behavior of the one-state model, it is interesting to see how far adding a little heterogeneity can go in producing model responses that appear more in line with stylized facts. The answer is quite a long way. The addition of another state breaks the synchronization of the one-state model, resulting in much smoother impulse responses. The two-state model is calibrated as above with idiosyncratic technology shocks taking values of 0.92 and 1.08 and with each firm having an $80 \%$ chance of remaining in the same state and a $20 \%$ chance of transitioning into the alternate state. The model's aggregate behavior

is displayed in figure (17). First notice in panel D. that there is much less of a departure in price setting from what is observed in steady state. Firms largely ignore the aggregate shock; generating the required duration of prices requires large fixed costs enough that it 

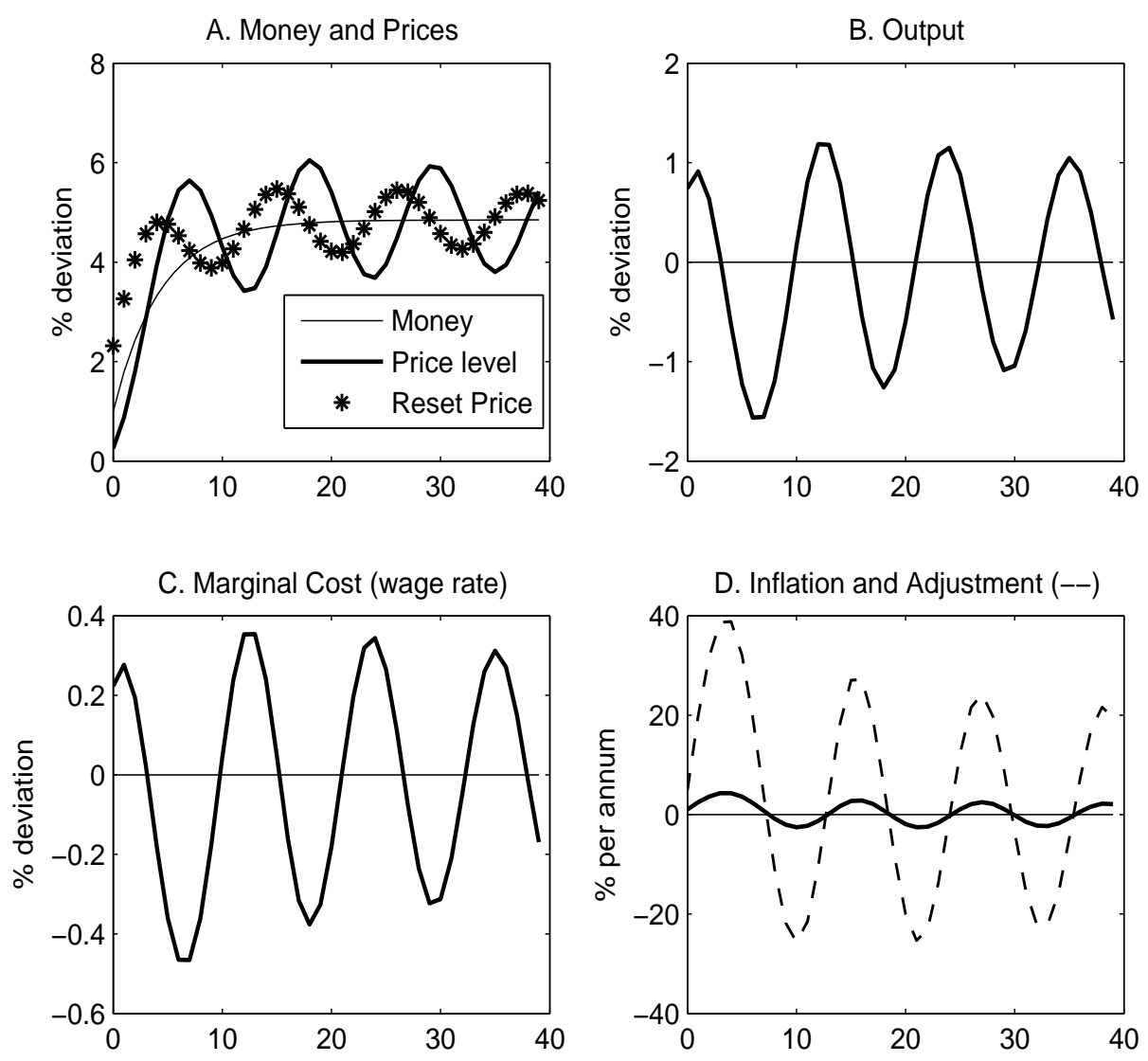

Figure 16: One State Model 

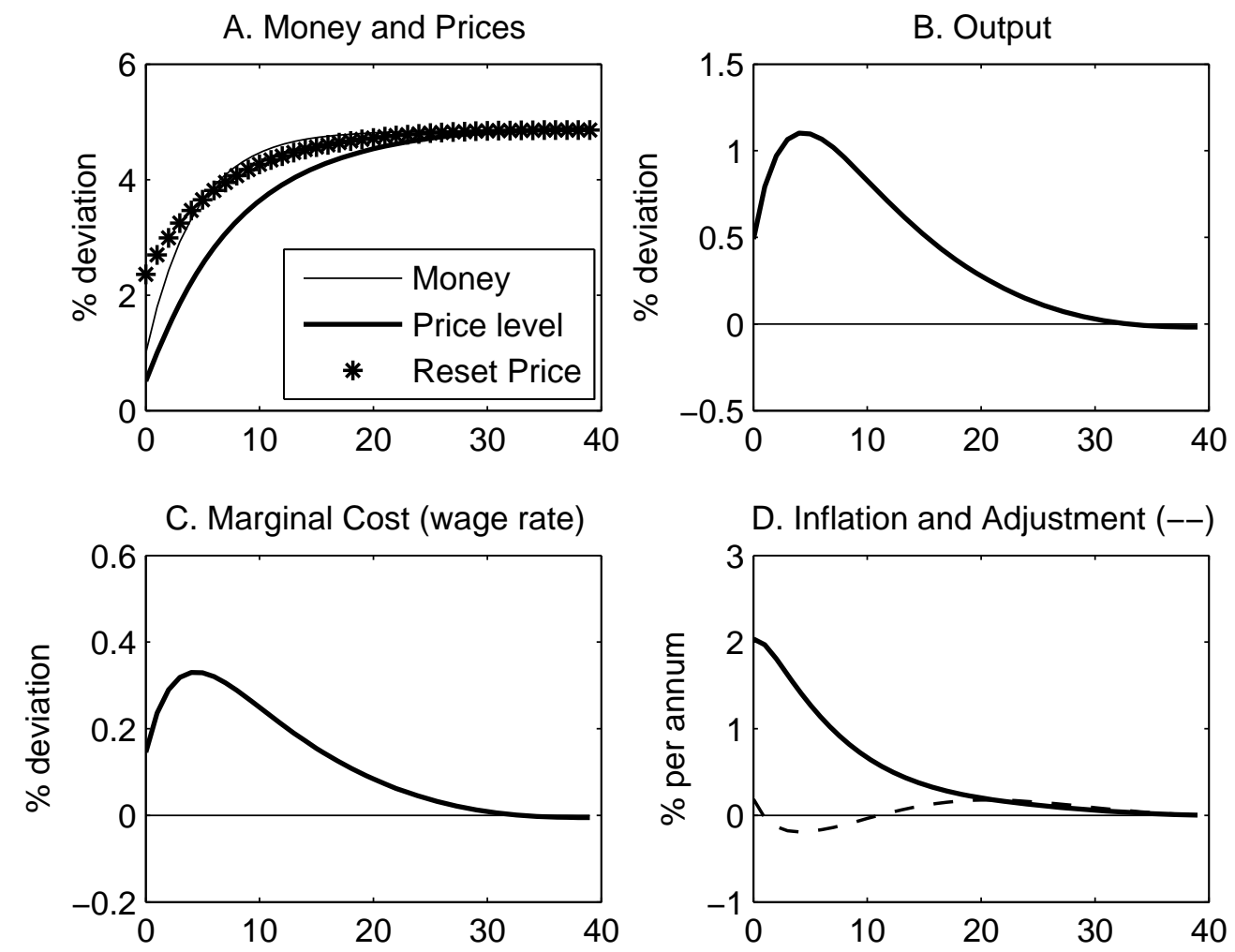

Figure 17: Two State Model

often pays to ignore relative price variations due to a relatively small aggregate disturbance. As a result the price level increases at less than the rate of the money stock and the response of output and inflation is highly persistent with significant effects two years out.

In part the persistence is driven by the low elasticity of marginal cost with respect to output (notice in Panel $\mathrm{C}$ of figure(17) that wages move only about one-third as much as output), but part of the persistence is due to firms not responding aggressively to the aggregate shock. Increasing the coefficient of relative risk aversion, as is done in figure (18), significantly dampens the model economy's response to the money shock, but there is still some endogenous persistence even when $\sigma=2$.

\subsection{Adding an additional state.}

Given the tremendous effect of moving from a one-state to a two-state model, one might suspect that adding yet a third state would have similar effects. In the benchmark case shown 


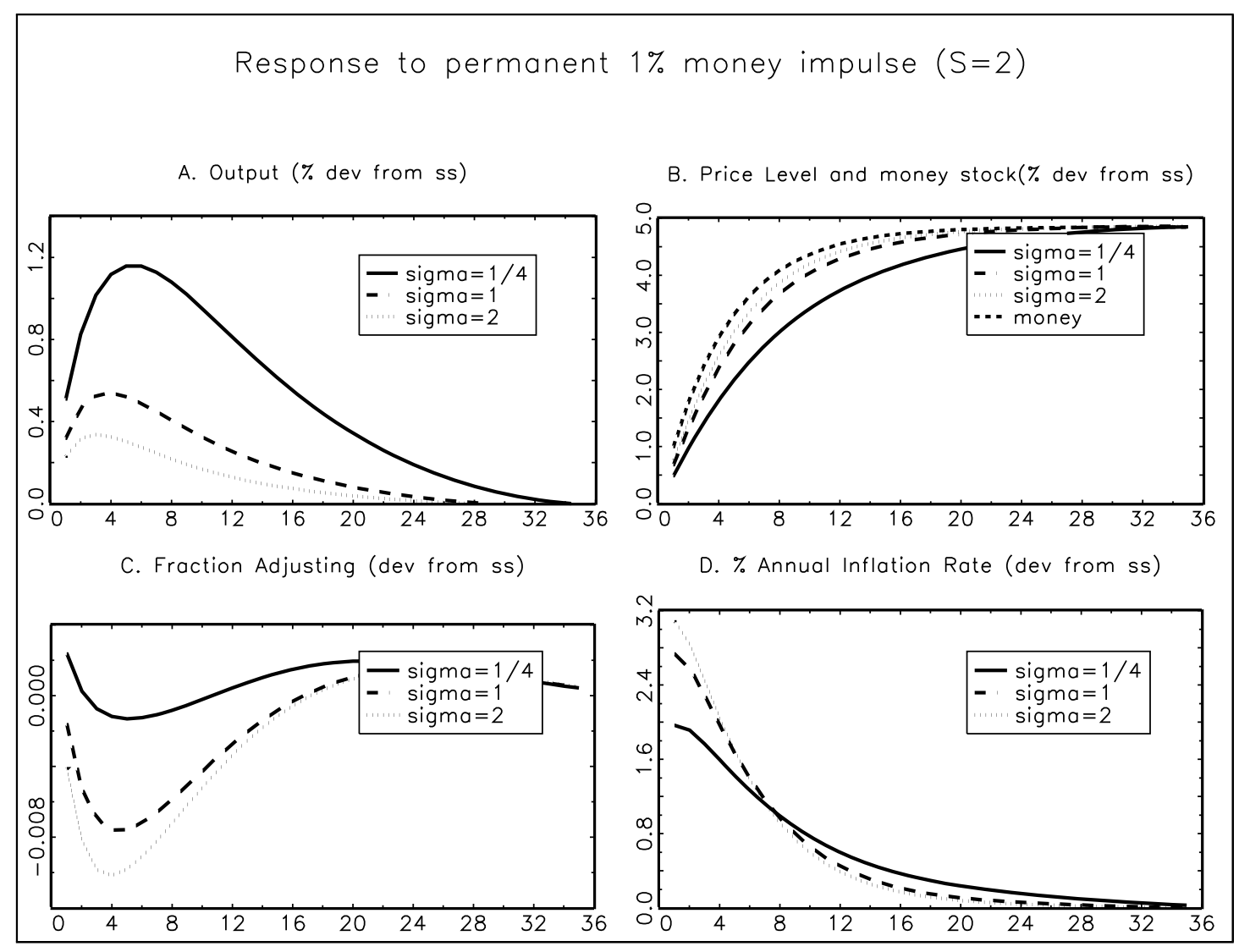

Figure 18: 


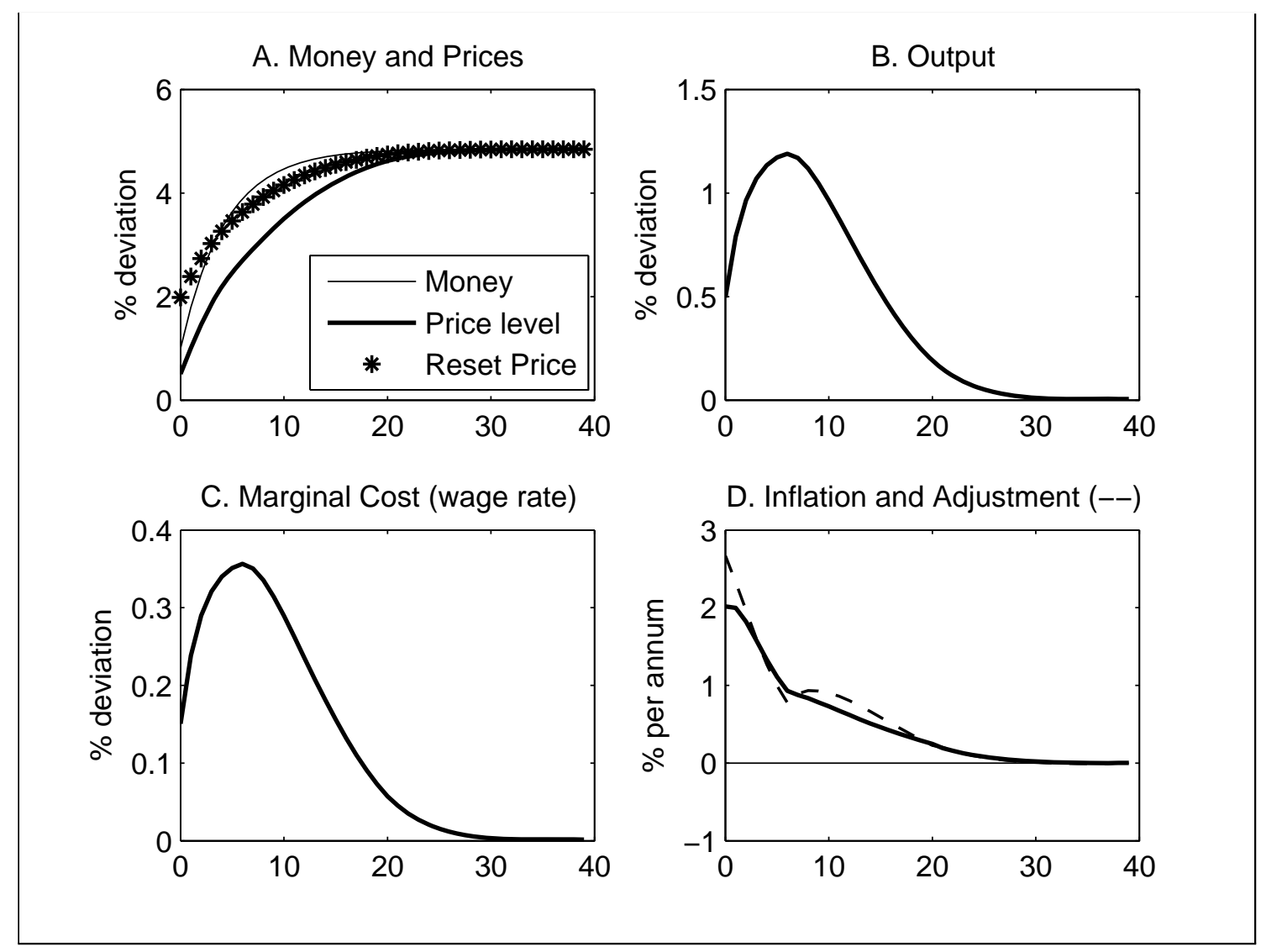

Figure 19: Three State Model

below, it does not. The impulse responses from the two and three-state models look fairly similar. With three states and the same degree of dispersion for the idiosyncratic shocks, as well as limited opportunity to move between extreme shocks, the three state benchmark model requires less costly price adjustment in order to match the average duration of price changes. The lower price adjustment costs result in more price adjustment in response to the money supply shock than occurs in the two-state model so more firms adjust on impact.

\subsection{The Model of Golosov and Lucas}

With the intuition obtained from the small model examples, we now turn to the larger more descriptive models of actual price changes. Recalling our steady state results for the GolosovLucas model, there were a lot of big price changes due to the model's concern for aggregate volatility in price changing. Further, as Midrigan (2006) has pointed out, the Golosov-Lucas model generates a large mass of firms desiring to raise their price in response to a money shock. This selection effect also means that because a lot of firms are adjusting, adjusting firms will react aggressively in response to the money growth shock. This is indeed what 


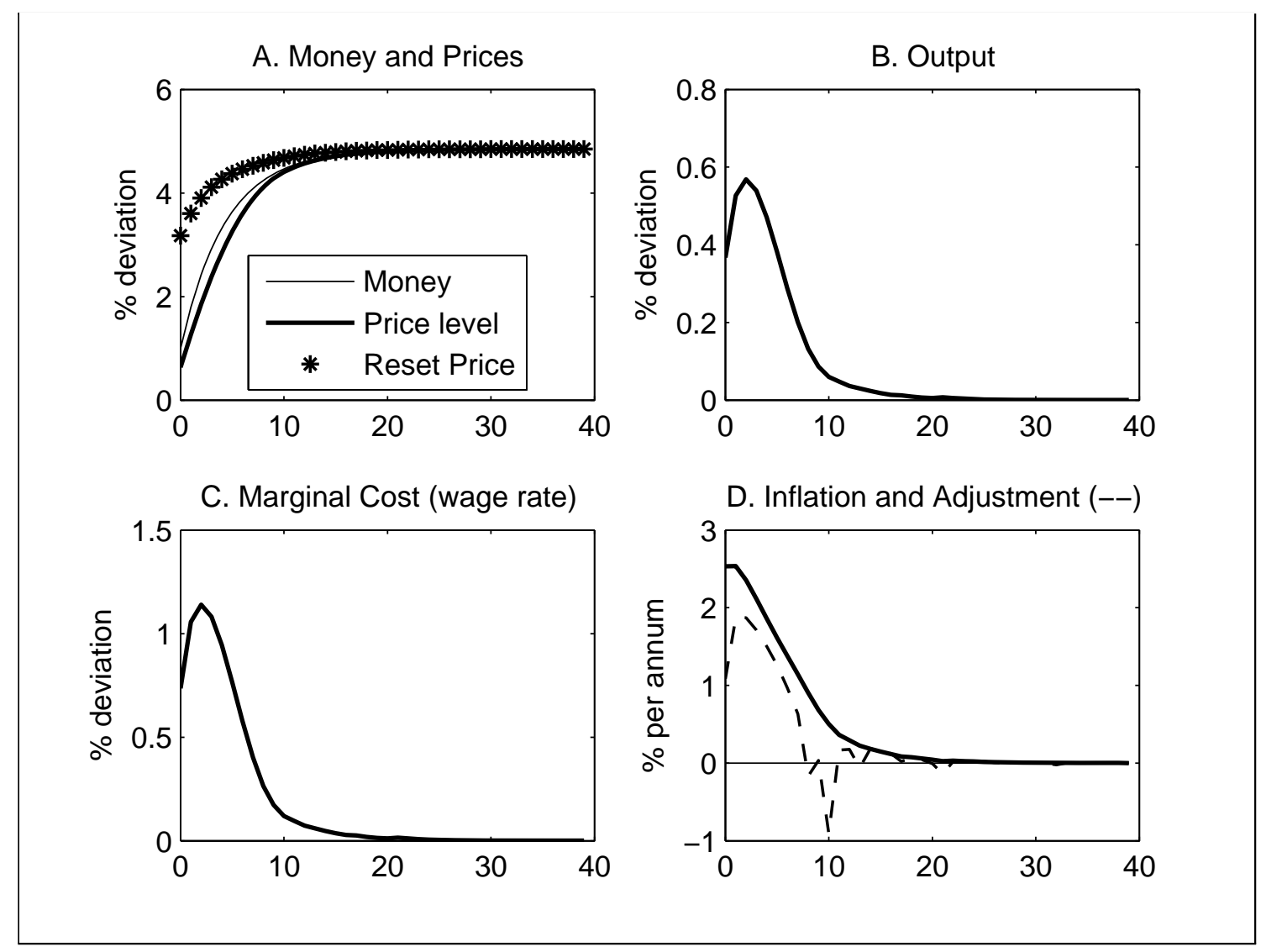

Figure 20: Golosov and Lucas Model

happens. The fraction of firms adjusting is large (lower right panel) and the jump in the reset price is almost three times as large as the money shock on impact (upper left panel). As a result, the price level moves almost one-for-one with the money supply and the response of output and inflation are short lived.

\subsection{The Model of Midrigan.}

Midrigan (2006) ingeniously gets around the selection effect, by incorporating joint production and price changing. If a firm changes the price of one of its products, it can change the price of its remaining products for free. The result is a radical departure from the steady state price distribution and hazard functions of the Golosov and Lucas model. In Midrigan's model, state-dependence in the presence of firm heterogeneity in marginal cost does not preclude the model from generating endogenous persistence in economic activity. Our approximation of Midrigan's model shares many of these features as well. First, notice that the fraction of firms deciding to adjust due to the shock is half that obtained in the GolosovLucas model, and that adjusting firms do not raise their price nearly as aggressively. The 


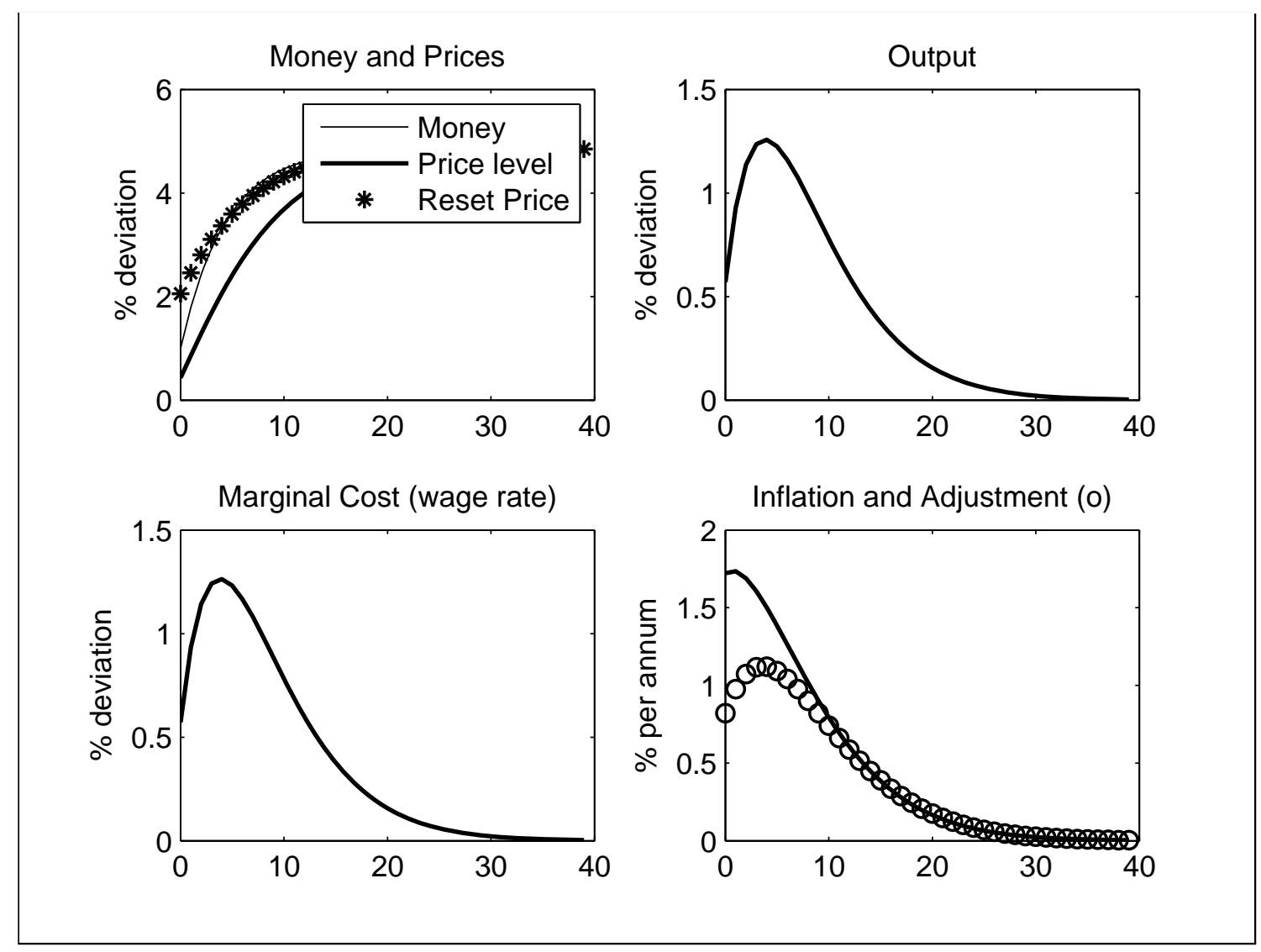

Figure 21: Midrigan Model

first result is at odds with Midrigan's benchmark model, in that he obtains more adjustment than in the Golosov-Lucas model, so we have not totally captured all the features of his model. The second result is consistent with his model. Further, we get impulse responses for output and prices that look very similar to those reported in his paper. Even though marginal cost is moving one for one with output, there is still a significant departure from steady state at 18 months. This departure represents substantial endogenous persistence-recall the average duration of price changes in steady state is 4.5 months. Thus, by capturing a richer set of moments in price setting behavior, a state-dependent model is capable of producing interesting dynamics.

\subsection{A Model Matching the Klenow and Kryvtsov Distribution}

Given the promise of Midrigan's (2006) insights, we now wish to see if that promise carries over to a model calibrated to match the distribution of price changes found in a wider set of goods, namely those that make up the CPI. Rather than matching a few select moments of the price distribution, we have chosen to match the histogram in figure (4). A model 


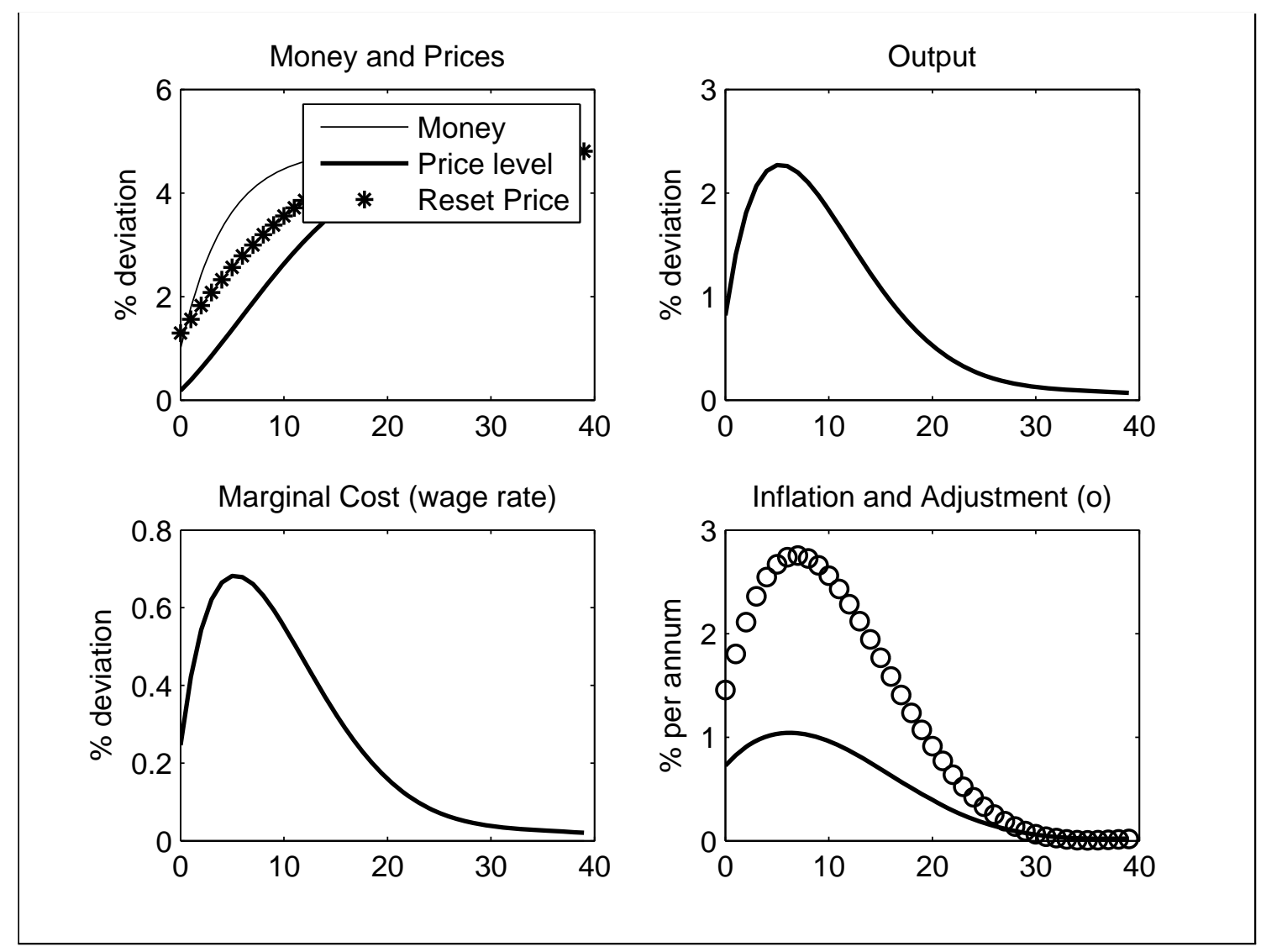

Figure 22: Klenow and Kryvtsov Model

calibrated in this way potentially matches actual price setting behavior quite well, so long as the moments generated from the dynamics do not depart too far from those found in steady state. The response of this model to a $1.0 \%$ money growth shock are shown in figure (22). Here we see somewhat greater willingness of firms to reset prices in response to the shock than in our approximation to Midrigan, but these firms price less aggressively. The less aggressive response of price changes translates into persistence in both output and inflation, and both variables impulse responses are humped shaped. Of note is the feature that output's peak response occurs slightly before that of inflation and that the relative magnitude of the peak responses are in line with the estimated impulse response functions in Christiano, Eichenbaum, and Evans (2005) The responses generated by the model are about half as persistent as those estimated in their paper, but we find that quite impressive given the simplicity of the model. From the vantage point of the last two experiments, it appears that incorporating firm level heterogeneity into a setting of state-dependent pricing holds significant promise for replicating both micro and macro evidence on price setting behavior. 


\section{Summary and Conclusions}

\section{References}

\section{References}

[1] Ball, L., Romer, D.,1990. Real rigidities and the non-neutrality of money. Review of Economic Studies 57 (2),183-203.

[2] Ball, L.,Romer, D., 1991. Sticky prices as coordination failure. American Economic Review 81 (3), 539-52.

[3] Bils, M. and P. Klenow, "Some Evidence on the Importance of Sticky Prices", Journal of Political Economy 112, October 2004, 947-985.

[4] Burstein, Ariel and Christian Hellwig,"Prices and Market Shares in a Menu Cost Model," manuscript September 2007.

[5] Caballero, R., Engel, E., "Microeconomic rigidities and aggregate price dynamics", European Economic Review 37 (1993, no.4), 697-717.

[6] Caballero, R.,.Engel, E., 1999. "Explaining investment dynamics in U.S. manufacturing: a generalized (S, s) approach," Econometrica 67 (1999, no. 4), 783-826.

[7] Calvo G. 1983. "Staggered Prices in a Utility Maximizing Framework" Journal of Monetary Economics, 383-398.

[8] Caplin, A., Spulber,D., 1987, "Menu costs and the neutrality of money", Quarterly Journal of Economics 102 (4), 703-726.

[9] Caplin, A., Leahy, J., 1991. "State-dependent pricing and the dynamics of money and output", Quarterly Journal of Economics 106 (3), 683-708.

[10] Christiano, Lawrence J., Martin Eichenbaum, and Charles R, Evans, "Nominal Rigidities and the Dynamic Effects of a Shock to Monetary Policy," Journal of Political Economy, 113(1), February 2005, 1-45.

[11] Dixit, A.K., and Joseph E. Stiglitz (1976). "Monopolistic Competition and Optimum Product Diversity", American Economic Review, 67, 297-308. 
[12] Dotsey, M., King, R.G., Wolman, A. L., 1999. State-dependent pricing and the general equilibrium dynamics of money and output. Quarterly Journal of Economics 114 (3), $655-90$.

[13] Dotsey, M., and R.G. King, "Implications of State-Dependent Pricing for Dynamic Macroeconomic Models," Journal of Monetary Economics, January 2005.

[14] Dotsey, M., and R.G. King, "Production, Pricing, and Persistence," forthcoming Journal of European Economic Association, September 2006.

European Central Bank

[15] Gertler, Mark and John Leahy, 2008, A Phillips Curve with an Ss Foundation," Journal of Political Economy, 116 (3), 533-572.

[16] Golosov, M. and R.E. Lucas, 2003. Menu costs and Phillips curves. NBER Working Paper \#10187.

[17] Kemeny, J. G. and Snell, J. L. Finite Markov Chains. New York: Springer-Verlag, 1976.

[18] Kimball, M., S., 1995. The quantitative analytics of the basic neomonetarist model. Journal of Money, Credit, and Banking 27 (4 part2), 1241-77.

[19] King, R.G. and J.K. Thomas. "Partial Adjustment without Apology", forthcoming International Economic Review, September 2006.

[20] Klenow, P., and O. Kryvtsov, "State-Dependent or Time-Dependent Pricing: Does It Matter for Recent U.S. Inflation?" June 2004, http://www.klenow.com.

[21] Mankiw, N. G., 2001. "The inexorable and mysterious trade-off between inflation and unemployment". The Economic Journal 111 , C45-C61.

[22] Midrigan, Virgiliu, 2006. "Menu Costs, Multi-Product Firms, and Aggregate Fluctuations." Manuscript.

[23] Nakamura, Emi and Jon Steinsson, "Five Facts About Prices: A Reevaluation of Menu Cost Models," manuscript April 2007.

[24] Willis, J., 2001. Magazine prices revisted. working paper 01-15 Federal Reserve Bank of Kansas City.

[25] Woodford, M., 2003. Interest and Prices: Foundations of a Theory of Monetary Policy. (Princeton University Press, Princeton). 
[26] Yun, T., 1996. Nominal price rigidity, money supply endogeneity, and business cycles. Journal of Monetary Economics 37 (2), 345-70. 
